\title{
Learning assistant approaches to teaching computational physics problems in a problem-based learning course
}

\author{
Alanna Pawlak* \\ Center for STEM Learning, University of Colorado Boulder, Boulder, Colorado 80309, USA \\ Paul W. Irving \\ Department of Physics and Astronomy, Michigan State University, East Lansing, Michigan 48824, USA \\ and CREATE for STEM Institute, Michigan State University, East Lansing, Michigan 48824, USA \\ Marcos D. Caballero \\ Department of Physics and Astronomy, Michigan State University, East Lansing, Michigan 48824, USA; \\ CREATE for STEM Institute, Michigan State University, East Lansing, Michigan 48824, USA \\ and Department of Physics and Center for Computing in Science Education, \\ University of Oslo, Oslo, Norway
}

(Received 6 February 2019; accepted 12 May 2020; published 19 June 2020)

\begin{abstract}
An increasing number of introductory physics courses are seeking to incorporate "authentic practices," and a large area of focus in this trend is the incorporation of computational problems into the curriculum. These problems offer students an opportunity to engage with the programming practices and numerical problem-solving methods used by physicists. Understanding how instructors approach teaching such problems is essential for improving instruction and problem design. We conducted a phenomenographic study using semistructured interviews with undergraduate learning assistants in a problem-based introductory mechanics course that incorporates several computational problems. The learning assistants' prior involvement as students, along with their relatively fewer experiences with programming and physics compared to the faculty instructors, give them a unique perspective on teaching in the course. We present here the results of our analysis: the identification of four approaches that learning assistants make take to teaching computational problems in this course. These approaches, programming focus, learning physics via computation focus, computation as a tool focus, and shifting perceptions of learning focus, provide a lens for understanding the different ways learning assistants perceive computation, the degree to which they take up course-intended learning goals surrounding computation, the factors that may impact the approaches they take, and how we might affect their approaches through training and support.
\end{abstract}

DOI: 10.1103/PhysRevPhysEducRes.16.010139

\section{INTRODUCTION}

In order to meet the repeatedly identified need for wellprepared science, technology, engineering, and mathematics (STEM) majors in both modern academia and industry [1-5], undergraduate physics education has adapted in many ways [6-10]. One strategy has been the increased incorporation of collaborative learning activities and the development of collaborative learning environments. In these contexts, students work primarily with each other in groups, with instructors facilitating their work rather than

*alanna.pawlak@colorado.edu

Published by the American Physical Society under the terms of the Creative Commons Attribution 4.0 International license. Further distribution of this work must maintain attribution to the author(s) and the published article's title, journal citation, and DOI. lecturing [11-19]. Problem-based learning, for example, has students work in groups to solve complex problems framed in realistic contexts, often without explicitly stated questions [11,19-21]. Problem-based learning environments can require careful facilitation to ensure that students are having productive learning experiences. Instructors may need to moderate group dynamics and guide students' learning in a way that is not demanded of them in a traditional lecture course [11,22-24]. This context offers a rich environment in which to study instructors' enacted teaching methods, that is, their practices, and their beliefs about teaching and learning.

To give students this level of attention, collaborative learning environments often employ both teaching assistants and faculty members as instructors in the classroom [24-28]. Teaching assistants may be graduate students or undergraduate students, with the latter often referred to as learning assistants. Learning assistants are a unique 
population of instructors, as they may be best suited to understand their students' perspectives, and also may not have a great deal more experience with the content than their students [26,27]. The teaching practices and beliefs of learning assistants, especially those surrounding computation, have not been greatly studied however [29-31], and so there is a need for further research on this group.

In tandem with transforming the structure and instruction of learning environments in these ways, there has been a push to incorporate authentic practices into physics education in order to better prepare students for academia and industry $[32,33]$. One particular practice that has had an increasing emphasis is computation [19,33-39]. The practice of modern science relies on the use of computers to model and simulate phenomena that are impossible or impractical to study analytically, but historically, students have received little explicit instruction in these skills [33]. Computational exercises, that is, exercises that require students to model or simulate physical scenarios numerically, are beginning to be more incorporated into undergraduate physics courses. Studying the ways in which these exercises are being implemented and taught is important for making them as productive as possible for students.

We conducted a study taking place at the intersection of these three developments in physics education: problembased learning, undergraduate learning assistants, and computational problems. We interviewed learning assistants who had taught in a section of an introductory mechanics course that is taught in a problem-based learning style and that incorporates several computational problems. Our aim was to examine how they approached teaching computational problems in this environment, because understanding how these uniquely positioned members of the teaching team work in such a complex environment provides valuable insight into how we can best design and implement computational work for students, and gaining such insight will be increasingly important as computation becomes more prevalent in physics curricula. In particular, better understanding how learning assistants approach teaching computational problems could allow for the development of training and supports that encourage them to teach in ways that are most in line with the course goals surrounding computation. To examine the learning assistants' approaches to teaching computational problems, we conducted a phenomenographic analysis [40-43] of phenomenographic interviews with 12 physics learning assistants, resulting in the development of four approaches they may take to teaching computational problems in a problembased learning course. We present here these approaches, the process of their development, and their implications. First we will review the relevant literature, then provide a description of our methods and study design, and finally present and discuss our results.

\section{BACKGROUND}

The study presented here draws on literature from three diverse but related areas of research: learning assistants, problem-based learning, and computation. The participants were undergraduate learning assistants, a relatively little studied population [27,29-31], the course was taught in a problem-based learning style, a context rich with complex interactions among students and instructors [11,20,21,23], and the course made use of computational problems, a unique type of activity at the center of the push to incorporating authentic practices into physics education [19,33-39]. A review of the literature on these three subjects will be provided here.

\section{A. Problem-based learning}

Problem-based learning was developed in the field of medical education in order to give medical students better opportunities to apply their knowledge in realistic scenarios $[44,45]$. Since then, it has been adopted in many contexts, across different education levels and disciplines [11,20$22,46]$. Problem-based learning is founded upon a shift from the instructor-centered approach of traditional lecture environments, to a student-centered approach, wherein students must navigate complex problems together [11,20-22,24]. There are a variety of definitions and implementations of problem-based learning, but these learning environments are often characterized by students working in collaborative groups, instructors functioning as guides rather than lecturers, and problems that require students to leverage decision making, planning, and problem-solving skills. The goal of these learning environments is that students develop conceptual understandings and discipline-relevant skills through the process of their largely self-directed work through the problems $[11,20-22,44,45]$. The dynamic structure and complex tasks in problem-based learning environments make them a rich environment for educational research, and such research has been done on the perspectives of both instructors and students.

The student perspective of problem-based learning has been studied in several ways. Many quantitative studies have measured the conceptual learning of students in these environments and found that they are more effective than traditional pedagogies $[11,47-50]$. Dochy et al. conducted a meta-analysis of such studies and found that they overwhelmingly indicated that problem-based learning has positive impacts on students' learning [49]. Barron et al. found that middle school students' learning improved by several metrics when they engaged in problem-based learning activities [11]. In post-secondary physics education specifically, multiple studies have echoed these results. Van Kampen et al. found that students' exam performance improved after the development of a problem-based learning module [47]. Selcuk et al. investigated the impact of problem-based learning on preservice teachers in a physics course and found that it improved their achievement on 
physics activities [48]. Using the Force Concept Inventory, Sahin et al. found that students who had engaged in problem-based learning had greater learning gains than those in traditionally taught courses [50].

Several studies have measured the impact of problembased learning on student engagement and perceptions. In the previously mentioned study by Van Kampen et al., results also indicated that the problem-based learning module they implemented had a positive effect on how interesting and relevant students found the physics content [47]. Ahfeldt et al. conducted a quantitative study to assess the impact of problem-based learning on student engagement, and found that it resulted in greater engagement than traditional courses [51]. Selcuk et al. similarly found that problem-based learning increased students' interest [48]. Results have not been universally positive, however, with Sahin et al. finding that problem-based learning did not appear to have any benefits over traditional courses when comparing student attitudes and beliefs as measured by the Colorado Learning Attitudes about Science Survey [50].

There has also been research examining other aspects of students' experiences in problem-based learning environments. Raine et al. found that students perceive problembased learning to effectively model how work is done outside of classrooms. They also found that students are cognizant of and appreciate the approach to learning that problem-based learning encourages [20]. Selcuk et al. similarly found that problem-based learning was effective at encouraging students to take up a deep approach to learning [48]. Through interviews with students, Cockrell et al. identified "ownership of knowledge" as a salient characteristic of problem-based learning to students, with it being discussed in three contexts: group dynamics, tutor feedback, and metacognitive awareness [21]. Chiriac developed a framework to identify and describe the group processes that students engage in when working in problem-based learning environments [52].

It is also important to understand the instructor perspective of problem-based learning environments, since these environments require just as radical of a shift in approach of instructors as they do of students [11,22-24]. While instructors in lecture-based environments may attend primarily to the transmission of content, problem-based learning environments require instructors to interact with their students, foster productive interactions among their students, and allow students to approach the problems in their own ways, while still guiding them towards learning outcomes. These considerations are complex and result in a myriad of approaches and beliefs that instructors may bring to problem-based learning. Barron et al. identified several design principles that instructors should consider when developing problem-based learning activities [11], while Maudsley discussed the ways that instructors must function in problem-based learning environments [24]. Abrandt et al. interviewed instructors who implemented problembased learning and found notable variations in their perceptions. They found that teachers considered problem-based learning from either the teacher perspective or from the learner perspective, and that they viewed their role to be either supportive or directive [23].

It is important to understand the perspective of instructors and how they approach their teaching in problem-based learning environments, as their practices will greatly affect students' learning and experiences. In particular, the way that more junior instructors in problem-based learning environments, such as undergraduate learning assistants, enact and perceive their teaching merits further study. Learning assistants can often comprise the majority of the teaching team in a problem-based course, and so understanding how they approach their teaching is essential to understanding these classrooms.

\section{B. Learning assistants}

The complex and collaborative nature of problem-based learning often requires greater facilitation than traditional lecture courses. In order to ensure that students are developing conceptual understandings of the physics content as they work through the complex problems, instructors must carefully guide their progress and be aware of their conversations and work [11,22-24]. To do this effectively, problem-based learning courses may employ teaching and learning assistants. Learning assistants provide a unique perspective, often being closer in experience with the content to their students than faculty members and graduate teaching assistants.

In the learning assistant model developed at University of Colorado Boulder, the learning assistant program is framed as not only a means to provide greater facilitation in their courses, but also as an opportunity to build the next generation of science teachers and make students more aware of the possibilities for teaching careers in STEM [27,53]. Much of the currently available research on learning assistants in physics has taken place in this context. There have been studies by Pollock et al. and Otero et al. conducted on the effects of employing learning assistants on student learning and course transformation sustainability, indicating that learning assistants have a valuable and positive impact on students and courses $[25,27]$. There has also been work done by Spike et al. examining how to best prepare learning assistants for their teaching assignments, resulting in the development of particular pedagogical models for learning assistant training [26]. Researchers have also investigated the long-term effects that participating in the learning assistant program has on individuals who go on to become teachers. In a study based on teaching observations, Gray et al. found that inservice teachers who had been learning assistants scored higher on measures of interactive teaching methods than peers who had not been learning assistants [30]. In a similar comparative study based on interviews with in-service teachers, Gray et al. found that former learning assistants 
were more comfortable implementing group work in their classrooms and were more likely to state that building a learning community was a goal in their implementation of group work [29]. Gray et al. also examined how current learning assistants described their use of questions when facilitating recitation sessions of introductory physics courses, finding that their comments suggested several different goals in asking questions, and several different perceptions of their role as a learning assistant, including facilitating physics content, facilitating students' sensemaking, shaping the learning environment, and professional growth [31]. Learning assistant programs have been implemented at other institutions as well, such as Florida International University [54] and Texas State University [55].

These studies provide valuable insight into learning assistants, however they have limitations. The learning assistants studied in the aforementioned studies worked in a variety of types of learning environments. For example, some worked in recitation sections where students worked on physics tutorials, which are relatively linear activities, with well-defined questions for students to answer sequentially [56]. This sort of activity is very different than the complex problems in problem-based learning, which can require students to determine their own goals and questions and may have multiple possible solutions [19]. This difference could lead to differences in how learning assistants approach and perceive teaching, and it is the teaching approaches of learning assistants in a problembased learning course that we examine in this study. In particular, we focus on how they perceive teaching problems that require students to engage in computational modeling.

\section{Computation in physics education}

For the past several decades, STEM education has increasingly incorporated computer-based activities and computational activities into the classroom [39,57-60]. While computer-based activities can be as simple as leveraging the internet for instruction and homework, "computational activities" here will refer to tasks which require students to engage in the numerical modeling, analysis, or simulation of phenomena. Physics education has pushed to incorporate these sorts of computational activities in the curriculum, as they provide students with valuable practice engaging in an authentic aspect of modern science, and also can aid students' understanding of physics concepts [33]. Early examples of computational activities in physics education varied greatly, with some being very open and giving students a great degree of control over and interaction with code $[39,58,59]$ and others being relatively closed and obscuring the underlying programming [57].

Some implementations of computational problems take elements of both styles, making some code visible and modifiable, but not expecting students to write programs from the ground up. In several different contexts, Caballero et al. developed computational physics problems in VPython, a variation of the Python language containing elements making it well suited to visual modeling. In these problems, students are given code that will run, but that does not yet correctly model the physical situation, known as "minimally working programs." Students' task is to then modify and add to the code so that it correctly reflects the physics of the situation [36,37]. This type of problem design is similar to the approach that Chabay et al. had taken previously to incorporating computational problems [38]. In addition to these various designs, computational problems can be incorporated into curricula in different ways. At Oregon State, computational problems like these have been intentionally woven into courses across the curriculum [35], while Kaplan describes the development of a stand-alone course on scientific computation at Macalester College [34]. Often, however, computational problems are incorporated into courses on an individual basis at the discretion of the instructor. Given this wide variation in how computational problems are implemented and their increasing incorporation into STEM education, research has been conducted in order to better understand how students and instructors experience and engage with these problems.

Research on the student experience of computational problems often focuses on assessing students' abilities to engage with the problems, and what identifying difficulties they encounter [36-38,61,62]. Chabay et al. found that when working on computational problems, students had more opportunities to use creativity in their problem solving and were better able to see connections across physical phenomena, however they sometimes struggled due to their lack of programming experience [38]. When students engaged in computational modeling using the logical rule-based format in the context of Wilensky et al., they were able to complete more complex problems, and engaged in more spontaneous question asking and exploration [62]. Caballero et al. found that the majority of students who had engaged in their style of computational problem were able to successfully solve new computational problems. They also observed that the students who were unsuccessful in the new problems had errors that suggested that a misunderstanding of the physics was limiting them, rather than indicating that the programming was a barrier to their success [36,37].

Some research has taken a broader approach when investigating the experiences of students working on computational problems. Lewis and Shah observed students working on pair programming exercises using an equity perspective, noting what inequities arose and suggesting methods to mitigate them [63,64]. Other studies have taken a phenomenographic approach to identify the different ways that students experience computational exercises. Booth et al. found four different approaches that college students in a programming class would take to 
their programming: structural, operational, constructual, and expedient [40]. In a similar phenomenographic study of introductory programming students, Bruce $e t$ al. identified five experiences that students may have with respect to programming: following, coding, understanding and integrating, problem solving, and participating, with each representing a student taking on a more expansive view of programming [65]. Studies such as these, and those on student achievement and difficulties regarding computational problems provide just one perspective, however, and it is important to also consider the teaching beliefs and practices of instructors who implement such problems.

Some research regarding instructors who incorporate computation into their classrooms has simply sought to identify the obstacles they perceive and to develop methods to help instructors overcome those barriers to implementation, such as that by Niess et al. [66]. With a similar motivation, Koehler et al. investigated the experiences of faculty and graduate students who took part in a workshop on incorporating technology into their courses, and found that having the experience embedded in their scientific disciplines had a significant impact on their perceptions [67]. Yerrick et al. examined the effect that perceived obstacles have on the different ways that teachers implement computational activities [68]. Hennessy also investigated variations in teachers' implementation of computational activities, finding several salient aspects of the teachers' experiences, such as leveraging the dynamic nature of simulations, focusing students' attention on key concepts, and often employing a teacher-directed facilitation style [69]. Phenomenography has also been applied to the instructor perspective of computational problems. Magana et al. interviewed faculty teaching undergraduate and graduate STEM courses that implemented computational simulation exercises. They found eight different intended outcomes that instructors may have in incorporating computation into their courses: to become aware of the role of computation in science, to make measurements, to find causal relationships in models, to test models, to validate results, to use computational techniques, to predict behavior, and to discriminate among possible models. They further argued that these eight intended outcomes represent increasingly higher order levels of thinking [70]. This sort of research on the perceptions of instructors is essential to understanding the implementation of computational problems, because instructors' beliefs and goals greatly impact how computational activities are carried out in practice [68].

The research on computational activities in physics (and STEM) education reviewed here gives a broad picture of ways computation is being implemented, how students perform on computational activities and what they struggle with, what instructors struggle with when teaching them, and some of the perceptions instructors have regarding them. While there has been some work done to qualitatively understand students' experiences of computational problems [40,65], there has been less done investigating the experiences of instructors [70]. Computational problems require instructors to attend to not only science content, but also computational practices in their teaching. Depending on the structure of the course, instructors might additionally need to carefully facilitate group interactions and problem-solving processes, as in problem-based learning. The research presented here takes place in a problem-based learning course that incorporated computational problems and that employed undergraduate learning assistants [19]. Teaching computational problems in this environment can be complex and challenging, and it is important to understand how instructors approach that challenge. In particular, better understanding the approaches and perceptions of learning assistants can allow us to better support their teaching and their development as teachers. In order to investigate the learning assistants' approaches, we employed phenomenography as our method.

\section{METHODOLOGY}

The research question of this study was

- What are the different approaches that learning assistants may take to teaching computational problems in a problem-based learning physics course?

In investigating this question, our goal was not to describe what methods they use in practice based on observations of their teaching, but rather to understand the approaches they identify with based on their opinions and self-described experiences. Phenomenography is a method uniquely suited to this type of study, wherein one seeks to identify different categories describing the ways that a group of individuals may experience a phenomenon. By using phenomenography, we were able to discover a set of approaches to teaching computational problems that spanned the learning assistants' experiences as a whole.

\section{A. Phenomenography}

Phenomenography developed as a research methodology in the 1970s through the work of Marton et al. in the context of education research as a means to understand student experiences [71,72]. Marton defined it as the study of the variations in the ways individuals perceive and understand phenomena, taking a relational stance, that is, arguing that the phenomena are not separate and exterior to the individual, but experienced through a relationship [73]. Phenomenography rests on the assumption that although individuals experience a given phenomenon in unique ways, by probing a group of individuals' experiences, one can uncover the essential variations in how they experience the phenomenon. These variations represent the underlying differences in experience that emerge when considering the group as a collective, and not differences 
observed by directly comparing individuals [74]. As a result, variations may appear not only across individuals, but also within individuals. Indeed, a phenomenographic study does not seek to account for the entirety of a given individual's experience of the phenomenon, nor does it seek to identify variations that allow for each individual to unambiguously exhibit only one variation of experience. Instead, the objective is to use the individuals' experiences to identify meaningful variations that give insight into how the collective may experience the phenomenon $[43,74,75]$.

The goal of a phenomenographic study is to find a set of categories that capture the variations in individuals' experiences of the phenomenon $[40,43,73,75,76]$. These "categories of description" should satisfy several criteria. Each category should describe a distinct way of experiencing the phenomenon of interest, the categories should have a logical relationship to one another, and the set of categories should be as concise as possible while still capturing the essential variations. The logical structure relating the categories is know as an "outcome space," and the outcome space is often hierarchical. In a hierarchical outcome space, categories represent increasingly sophisticated and detailed ways of experiencing the phenomenon. The hierarchical nature of many outcome spaces can provide a great deal of insight into individuals' experiences of the phenomenon. For example, since a given individual may exhibit several variations, if these variations represent different levels of sophistication of experience, we can gain insight into how individuals progress through the hierarchy to develop more sophisticated perceptions [77,78].

A great deal of phenomenographic work has focused on approaches to teaching and learning. A common result from these studies are such hierarchical outcome spaces, describing the identification of increasingly sophisticated levels of teaching and learning [40,65,70,79-83]. These results have great practical value in understanding learning environments, because they provide insight into how students adopt more sophisticated approaches to learning, and how teachers develop more sophisticated approaches to teaching. In this study, we investigated the teaching approaches of learning assistants, and specifically, their approaches when teaching computational problems in a problem-based learning course. By employing phenomenography, we were able to identify the underlying variations in how they approach teaching in this context, gaining insight into their beliefs as teachers and how we might support their development as teachers.

\section{STUDY DESIGN}

\section{A. Study context}

This study investigated the experiences of undergraduate learning assistants who had taught in an introductory calculus-based mechanics course. The course was a transformed section of the traditional lecture style course that is taught in problem-based learning style, known as "Projects and Practices in Physics" or "P Cubed" [19]. In its implementation of problem-based learning, P Cubed makes no use of lecture, and instead, students spend all time in the classroom working in groups of four on complex problems. These problems are written in such a way that they require that students work together and think intentionally about their problem-solving process. Each group is provided a laptop and a white board divided into four quadrants (assumptions or approximations, knowns, unknowns, and representations), which they are encouraged to use in order to organize their work. Over the course of the semester, 5 or 6 of the problems that students work on are computational (depending on whether it is a spring or fall semester).

Computational problems were incorporated into the course to give students experience with an authentic scientific practice, to show them the usefulness of computation in physics and problem solving, and to provide them with an additional way to engage with physics concepts. Additionally, the computational problems are designed in such a way that they support the overarching course goal of encouraging students to become more reflective and intentional about their learning, and they are designed to align with the problem-based learning approach. In the computational problems, students are given a physical situation that highlights the physics concepts being taught that week, and they are given a portion of VPython code. The given code is functional but incomplete; it will run without error, but it does not yet correctly model the physics relevant to the situation, a type of problem called a minimally working program [84]. The students' task for the class period is to modify and add to the code such that it correctly models the situation. The correctly modified code will render a visualization of the situation and/or graphs of physical quantities present in the situation. An example of a computational problem assigned in the course appears in Appendix A. While the computational problems implemented in the course may appear to involve simply adding a few lines of code, for the students in this course, the minimally working programs present a high level of complexity, and lead to discussions and problem-solving processes that are as complex and rich as those that students engage in during analytic problems. The computational problems were designed with problem-based learning principles such as encouraging group work, posing problems with multiple possible answer paths, requiring students to analyze, reason, and make decisions based on acquired knowledge and information, and offering learning goals that may shift as groups navigate their solutions. These shared aspects of the analytic problems and computational problems, and the similarity of students' engagement with both problem types, demonstrate the alignment of the computational problems with the problem-based learning approach of the course [85]. 
P Cubed meets for two hours twice a week, and has an enrollment of 100 students, most of whom are sophomore engineering majors. The course is open to all students, with enrollment occurring on a first come, first serve basis. Additionally, the course description on the university registration website makes it clear that it is taught in a problem-based learning style. P Cubed is taught by a teaching team composed of a physics faculty member (changing each semester), a graduate teaching assistant, and approximately 12 undergraduate learning assistants. The learning assistants are individuals who were successful as students in the course who are then invited to become instructors in the course. Corresponding to the student demographics, the learning assistants are primarily engineering majors. Learning assistants are invited to continue teaching the course as long as they are interested and available, and most choose to teach for several semesters.

In the classroom, all members of the teaching team function identically. Each instructor is responsible for two groups of students, guiding their progress through the concepts and problem of each day. Outside of the classroom, the teaching team has two preclass meetings every week (the day before each class session), and a postclass meeting at the end of each week. In the preclass meetings, the learning assistants work through the next day's problem in small groups, facilitated by the faculty members or graduate teaching assistant. In these meetings, the learning assistants have the opportunity to make sure they understand the concepts and solution themselves, and are also encouraged to think about how they will help their students navigate the problem and concepts. At the postclass meeting, all members of the teaching team summarize how their teaching went that week, and they can solicit help for any issues they are facing. Every member of the teaching team is responsible for writing individualized feedback for each of their students regarding their work that week. In addition to the aforementioned on-going responsibilities, the learning assistants also attend a day-long training workshop at the beginning of each semester, which goes over in-class teaching strategies, writing feedback, and course logistics.

\section{B. Data collection}

The participants in this study were 12 learning assistants from P Cubed, who had taught for at least one semester over the 7 semesters of the course's existence at the time of this study. They varied in major, class rank, gender, and semesters of experience teaching in P Cubed, shown in Tables I-IV.

They also had a wide variance in personal experiences with teaching and computation outside of $\mathrm{P}$ Cubed. These differences led us to believe that this would be a productive population for conducting a phenomenographic study, which depends on identifying variations as described previously $[40,43,75,76]$. In order to conduct a
TABLE I. Genders of the learning assistants interviewed.

\begin{tabular}{lc}
\hline \hline Gender & Number \\
\hline Female & 7 \\
Male & 5 \\
\hline \hline
\end{tabular}

TABLE II. Majors of the learning assistants interviewed.

\begin{tabular}{lc}
\hline \hline Major & Number \\
\hline Mechanical engineering & 3 \\
Biosystems engineering & 1 \\
Physics & 3 \\
Chemical engineering & 1 \\
Biochemistry & 1 \\
Computer science & 1 \\
Chemistry and Criminal justice & 1 \\
Biochemistry and Molecular biology & 1 \\
\hline \hline
\end{tabular}

TABLE III. Class ranks of the learning assistants interviewed.

\begin{tabular}{lc}
\hline \hline Class rank & Number \\
\hline Freshman & 0 \\
Sophomore & 2 \\
Junior & 4 \\
Senior & 6 \\
\hline \hline
\end{tabular}

TABLE IV. Semesters of experience teaching in P Cubed of the learning assistants interviewed.

\begin{tabular}{lc}
\hline \hline Semesters of experience & Number \\
\hline 1 & 2 \\
2 & 3 \\
3 & 2 \\
4 & 2 \\
5 & 2 \\
6 & 1 \\
\hline \hline
\end{tabular}

phenomenographic analysis of the learning assistants' approaches to teaching computational problems, we investigated their experiences via interviews. It is worth noting that the interviewer had a personal familiarity with the participants, as she had been a graduate teaching assistant in P Cubed and had worked with each of the participants. The interviewer strove to minimize any bias this might result in during the interviews and ensuing analysis.

\section{Interview protocol development}

In line with the goals of a phenomenographic study and with our phenomenon of interest, approaches to teaching computational problems, we developed a semistructured interview protocol aimed at probing the learning assistants' 
experiences teaching computational problems [76,86-88]. The semistructured nature of the protocol allowed for the interviewer to follow emergent threads that were salient to the participant, while also being sure to get as complete a picture of the individual's experience as possible. The questions on the protocol were developed based on several considerations. Of course, the majority of the questions directly probed their experiences and opinions on teaching computational problems in $\mathrm{P}$ Cubed. In addition to these questions, however, questions on the participants' backgrounds, opinions on the course structures (feedback, collaboration, etc.), and general opinions on teaching and learning were included. These were included in order to better contextualize their responses regarding the computational problems, and to also provide them with additional spaces to discuss computation and computational problems if they chose. The protocol underwent two rounds of revisions based on two pilot interviews. These revisions primarily involved restructuring the protocol in order to better follow conversational flow, and adding the questions regarding general opinions on teaching and learning, which had not been present in the initial version of the protocol. The interview protocol is presented in Appendix B.

\section{Conducting interviews}

The interviews were conducted over the course of approximately $1 \mathrm{yr}$, based on the availability of the interviewer and participants. Participants were solicited by contacting current and former P Cubed learning assistants, inviting them to participate and explaining the goals of the study, the nature of the interviews, and the compensation offered (a 10 gift card). The interviews were conducted one on one between the interviewer and each learning assistant, and lasted approximately $1 \mathrm{~h}$ and $15 \mathrm{~min}$. The interviews were open to following topics that the participants brought up spontaneously, and the questions on the interview protocol were not all explicitly asked in each interview or asked in the same order. The goal of the interviews was to develop as rich an understanding of the learning assistants' experiences as possible, so the primary goal throughout each interview was to provide the participants with as many opportunities to share their experiences in the ways that were most salient to them [76,86-88]. The interviews were audio and video recorded, the audio recordings were sent to an external company for transcription, and the transcripts were reviewed for accuracy upon receipt.

\section{ANALYSIS}

\section{A. Data reduction}

Analysis began with reviewing all the transcripts several times in order to become familiar with the dataset as a whole. After gaining familiarity with the full dataset, the data were reduced based on relevance to the phenomenon of interest. Because the interviews were open to following tangents, and because several background questions were asked (see Appendix B), there were portions of the transcripts that were not relevant to the participants' experiences with teaching computational problems. For example, participants may have discussed their motivations for becoming learning assistants, or described their teaching explicitly with respect to analytic problems. In an example of the latter, one learning assistant spoke about teaching the analytic problems, which occur on Tuesdays,

On Tuesday, the first question I'll ask them is, "What do you ultimately need to get? Where is your end goal?" They say, "Oh, this is our end goal." "Okay, what are the steps you need to take to get that?" That's on a Tuesday.

Portions of transcript such as these were neglected for the thematic analysis described next since they were not directly relevant to our phenomenon of interest, but they were retained in order to provide fuller context for participants' comments if necessary.

\section{B. Identification of preliminary themes}

Once identified, the reduced dataset was analyzed for emergent themes in participants' discussion of teaching computational problems. In phenomenography, themes are trends and common threads in individuals' experiences of the phenomenon of interest. Applied to our analysis, themes are common threads in what the learning assistants spoke about over the course of the interview related to their experiences teaching computation. Some of the themes identified in our data corresponded to questions that were directly asked by the interviewer, while others did not. In either case, the themes were identified based solely on the comments of the participants in the transcripts, and the researchers strove to analyze the transcript without bias towards any particular themes emerging. This process resulted in a preliminary set of seventeen emergent themes shown in Table V. These themes do not account for all of the reduced dataset. Some relevant portions of transcript were too unique or specific to be sorted into a theme. Examples include a learning assistant speaking on very specific role that he plays as computation expert on computation days, or extra preparation that a learning assistant engages in before she teaches computational problems. While these comments were interesting, they were not further analyzed. Since the goal of this study, and of any phenomenographic study, is to find the most concise way to capture the different ways that individuals may experience a phenomenon $[40,43,75,76]$, it is expected that not every relevant comment from the participants will be identified as belonging to a theme.

It is also worth noting that these themes are not necessarily mutually exclusive, and that there are portions of transcript that were coded as belonging to multiple themes. This is because in a given comment, a participant 
TABLE V. List of preliminary emergent themes identified in the data.

\begin{tabular}{l}
\hline \hline \multicolumn{1}{c}{ Preliminary themes } \\
\hline Differences between analytic and computational teaching \\
Written feedback \\
Varying levels of student programming experience \\
Different student approaches to computation \\
Differences in student behavior solving computation versus \\
analytic problems \\
What students should do when solving computation problems \\
Acceptable places to end computation days \\
Minimally working programs \\
Solution manuals \\
Why code in groups \\
Student challenges \\
Teaching challenges \\
Teaching physics versus teaching coding on computation days \\
In-class teaching strategies \\
Important things for students to take away \\
Purpose of computation \\
Student frustration
\end{tabular}

often discusses several dimensions of their experience at once. Thus one would not expect, and it is not a requirement that the themes be wholly orthogonal.

\section{Analysis of preliminary themes}

Once preliminary themes had been identified, individual themes were selected and examined in more detail to identify the variations within them. In phenomenography, a variation is a particular way that an individual may experience a theme surrounding the phenomenon of interest. For our analysis, variations are therefore the different ways that the learning assistants discussed the emergent themes surrounding teaching computation. This analysis began with the investigation of the themes that were most richly populated, and which had the strongest apparent tie to our phenomenon of interest. These themes were in-class teaching strategies, differences between analytic and computational teaching, and teaching physics versus teaching coding on computation days since all three had explicit references to how learning assistants teach in the classroom, along with important things for students to take away since it appeared to be related to learning assistants' motivations for their teaching. Through the process of identifying emergent variations within these preliminary themes, they were ultimately reorganized into three new themes: teaching outcome, teaching strategy, and characteristic to moderate. These three themes and their respective variations are shown in Tables VI-VIII.

Teaching outcome refers to what a learning assistant hopes their students gain from working on the computational problems as a result of their teaching. Teaching strategy refers to the techniques that a learning assistant may employ when teaching. Characteristic to moderate refers to what on-going element of students' experiences during class the learning assistant feels they must attend to and keep within certain bounds. The preliminary themes were restructured in this way because these themes better described the underlying features that emerged from the data. While the preliminary themes attended to the surface commonalities among the learning assistants' comments, focusing on the content of their statements, the themes shown in Tables VI-VIII are better grounded in the

TABLE VI. Variations within the teaching outcome theme, describing learning assistants' goals for their students.

\begin{tabular}{lc}
\hline \hline Variation & Teaching outcome variations \\
\hline Programming skill & A familiarity with the syntax and structures of code \\
Physics-code connection & An understanding of the relationship between the computational \\
& problems and the physics concepts \\
A new approach to learning & New perceptions and beliefs about learning \\
Capabilities of computation & An appreciation of the usefulness of computation \\
\hline \hline
\end{tabular}

TABLE VII. Variations within the teaching strategy theme, describing the techniques learning assistants use while teaching.

\begin{tabular}{ll}
\hline \hline & Teaching strategy variations \\
\hline Variation & \multicolumn{1}{c}{ Definition } \\
\hline Focus on navigating programming errors & Identify and help students overcome programming errors \\
Encourage reflection on coding & Promote deeper thought on the function of computation \\
Leverage collaboration & Stimulate group discussion of ideas \\
Leverage affordances of computational & Utilize elements unique to computational problems in teaching \\
problems & \\
\hline \hline
\end{tabular}


TABLE VIII. Variations within the characteristic to moderate theme, describing what aspects of a group's experience a learning assistant feels they must monitor and influence.

\begin{tabular}{lc}
\hline \hline \multicolumn{1}{c}{ Characteristic to moderate variations } \\
\hline Variation & \multicolumn{1}{c}{ Definition } \\
\hline $\begin{array}{l}\text { Student attitudes } \\
\text { Student attention to } \\
\text { programming details } \\
\text { Student work pace }\end{array}$ & $\begin{array}{c}\text { Avoid students focusing on } \\
\text { too unhappy } \\
\text { Ensure students complete the activity }\end{array}$ \\
Impact of course design & $\begin{array}{c}\text { Mitigate the effect of the } \\
\text { limitations of course structures }\end{array}$ \\
\hline \hline
\end{tabular}

substantive differences in the levels of considerations the learning assistants' discussed.

The next preliminary themes analyzed were the purpose of computation theme, because it was hypothesized that a learning assistant's perception of the usefulness of computation would have a notable effect on their teaching, and the student frustration theme because it was suspected that it may be accounted for already by the student attitudes variation of the characteristic to moderate theme. This was found to be largely correct, and the majority of the portions of transcript in the student frustration theme not identified as student attitudes were nonetheless accounted for by variations within the already identified themes. The variations ultimately identified within the purpose of computation theme appear in Table IX, retitled as utility of computation.

\section{Development of categories of description}

The final steps of developing the four themes presented thus far were informed by developing preliminary categories of description. The goal of a phenomenographic study is to develop a set of categories of description that capture the different ways individuals may experience the phenomenon of interest $[40,43,75,76]$. A category of description is composed of a variation from each theme, such that together, the combination of variations form a coherent experience an individual might have of the phenomenon of interest. With this goal in mind, we considered the variations seen in the themes analyzed thus far. This was done at this point in analysis because the preliminary themes analyzed thus far indicated a rich variation in experiences teaching computational problems and provided a great deal of information with which to develop preliminary categories of description. Furthermore, the data analyzed thus far represented a great majority of the reduced dataset to be considered. Based on these considerations, it was decided that it was an appropriate point at which to begin developing categories of description by looking across themes. This stage of analysis constituted a secondary thematic analysis within the bounds of the already identified themes, where we now analyzed the variations for emergent threads that described coherent approaches to teaching computational problems, and a set of preliminary categories were developed. The development of these categories aided in the finalization of the themes and variations in Tables VI-IX, which in turn informed the refinement of the categories of description. This mutually informative process ultimately resulted in the final categories of description shown in Table X, which are described in detail in Sec VI.

Having arrived at a set of coherent categories of description, the final step in analysis was to review the remaining preliminary themes in Table $\mathrm{V}$ and confirm that they were accounted for within the four themes identified thus far, or that they could justifiably be neglected. Several of the remaining preliminary themes were already accounted for within the themes in Tables VI-IX upon closer analysis. Specifically, it became evident that some preliminary themes had emerged based on characteristics that were superficial in light of the deeper themes and categories that had developed. The written feedback, varying levels of student programming experience, acceptable places to end computation days,minimally working programs, solution manuals, and teaching challenges themes were largely already described by the themes in Tables VI-IX. A majority of the portions of transcript that had initially been sorted into these preliminary themes were determined to be simply context-specific discussions of

TABLE IX. Variations within the utility of computation theme, describing what learning assistants perceive the usefulness of computation to be.

\begin{tabular}{lc}
\hline \hline & Utility of computation variations \\
\hline Variation & \multicolumn{1}{c}{ Definition } \\
\hline $\begin{array}{l}\text { Programming is an important skill } \\
\text { Computation aids content learning }\end{array}$ & $\begin{array}{l}\text { Programming is a significant part of modern society } \\
\text { Computation makes difficult }\end{array}$ \\
$\begin{array}{l}\text { problems easier } \\
\text { Computation offers space for }\end{array}$ & Computation is valuable in modeling and solving complex problems \\
broader skills & Skills valuable beyond the classroom and computation \\
\hline \hline
\end{tabular}


TABLE X. Final categories of description. Each category of description represents an approach to teaching computation based on learning assistants' experiences in the classroom. Column 1 gives the name of each category of description, and columns $2-5$ indicate which variation within each theme that category of description is associated with. Note that columns 2-5 are equivalent to Tables VI-IX.

\begin{tabular}{|c|c|c|c|c|}
\hline $\begin{array}{l}\text { Category of } \\
\text { description }\end{array}$ & $\begin{array}{l}\text { Utility of } \\
\text { computation }\end{array}$ & $\begin{array}{l}\text { Teaching } \\
\text { outcome }\end{array}$ & $\begin{array}{l}\text { Characteristic } \\
\text { to moderate }\end{array}$ & Teaching strategy \\
\hline Programming focus & $\begin{array}{l}\text { Programming is } \\
\text { an important skill }\end{array}$ & Programming skills & Student work pace & $\begin{array}{l}\text { Focus on navigating } \\
\text { programming errors }\end{array}$ \\
\hline $\begin{array}{r}\text { Learning physics via } \\
\text { computation focus }\end{array}$ & $\begin{array}{c}\text { Computation aids } \\
\text { content learning }\end{array}$ & $\begin{array}{r}\text { Physics-code } \\
\text { connection }\end{array}$ & $\begin{array}{l}\text { Impact of course } \\
\text { design }\end{array}$ & $\begin{array}{l}\text { Leverage affordances of } \\
\text { computational problems }\end{array}$ \\
\hline $\begin{array}{l}\text { Computation as } \\
\text { a tool focus }\end{array}$ & $\begin{array}{l}\text { Computation makes } \\
\text { difficult problems easier }\end{array}$ & $\begin{array}{r}\text { Capabilities of } \\
\text { computation }\end{array}$ & $\begin{array}{l}\text { Student attention } \\
\text { to programming details }\end{array}$ & $\begin{array}{l}\text { Encourage reflection } \\
\text { on coding }\end{array}$ \\
\hline $\begin{array}{l}\text { Shifting perceptions } \\
\text { of learning focus }\end{array}$ & $\begin{array}{l}\text { Computation offers } \\
\text { space for broader skills }\end{array}$ & $\begin{array}{l}\text { A new approach to } \\
\text { learning }\end{array}$ & Student attitudes & Leverage collaboration \\
\hline
\end{tabular}

learning assistants' teaching. An example appears in the quote below,

[Using minimally working programs] impacts my teaching a lot because I feel like I only really focus on the things I teach them how to code, like understand the code, or more like the while loops. I teach them about what's already there and it's not like I'm starting like this is what code is, and this is how you code things, like a coding class would teach you. And so you can focus specifically on while loops and if statements, which really limits the amount of coding you're necessarily teaching them and you can focus more on the physics side of it.

While this learning assistant discusses minimally working programs in this excerpt, he ultimately is discussing that he seeks to avoid programming becoming a distraction. He emphasizes how he teaches computational elements like while loops and if statements, but does not get into the details of programming "like a coding class would." In this way, he expresses an attention to ensuring that those details do not become the students' focus. Thus, this excerpt is accounted for within the characteristic to moderate theme, specifically the student attention to programming details variation. The majority of the transcript sorted into the aforementioned preliminary themes was similarly better captured by the final themes.

Other preliminary themes were eliminated because they were found to not be central to our phenomenon of interest: learning assistants' approaches to teaching computational problems. The different student approaches to computation, differences in student behavior solving computation versus analytic problems, what students should do when solving computation problems, why code in groups, and student challenges themes were neglected because upon closer analysis, it was observed that while they did relate to learning assistants' perceptions of the computational problems, they did not provide insight into their approaches to teaching. In the student challenges, different student approaches to computation, and differences in student behavior solving computation versus analytic problems themes, learning assistants simply shared their observations of students, but did not connect these observations to their teaching. In the why code in groups theme (and the portions of the written feedback, varying levels of student programming experience, minimally working programs, and solution manuals themes that were not already accounted for by the final themes), learning assistants shared their opinions on the design of $\mathrm{P}$ Cubed, but again, did not connect these opinions to their teaching and did not elaborate sufficiently for their comments to give insight into their approach to teaching. In the what students should do when solving computation problems theme, learning assistants discussed the ideal problem-solving approach to computational problems, but did not describe why they held that belief or how it impacted their teaching. In all of these cases, interesting information about the learning assistants' perceptions of computational problems was revealed, but this information was not productive in describing their teaching approach.

For example, in the student challenges theme, one learning assistant discussed a problem that requires the students to model the motion of a rotating disk, in which the given code defines the $y$ axis to be the axis of rotation. She notes that this causes confusion for the students, because in analytic problems, the $z$ axis is often taken to be the axis of rotation.

I think, I mean like, I feel like they are going to get confused about anything new, but that one, I know there was a lot of confusion with the different things. There was an axis and the origin, and so I know I had discussions with both my groups about what those meant and think it's also confusing because it's like in the z axis, but I think on the code it's on the y axis, something like that. So, I don't know, all of those changes, kinda I think make those a little bit difficult to understand. 
The learning assistant's discussion of how students struggle with coordinate systems in the computational problems gives some insight into her opinions on computational problems and the students, but it does not give insight into how she approaches her teaching overall. While she does state that she "had discussions" with her groups about this particular issue, it does not reveal her teaching strategy or teaching outcome, and it does not give information that is helpful in identifying the variations in learning assistants' teaching approaches.

Having thus confirmed that the themes and variations in Tables VI-IX were sufficient to meaningfully describe the learning assistants' experiences as they related to their teaching approaches, and that cohesive categories of description based on groupings of variations within them could be developed (described in Sec. VI), analysis was concluded.

\section{E. Validation}

In addition to the processes described here, results were subject to validation throughout analysis and upon completion. The entire analysis process was conducted in regular consultation with a researcher with expertise in phenomenography. All analysis decisions were subject to scrutiny and discussion, and had to be adequately justified through evidence from the transcript and defensible arguments. This included decisions to merge themes or variations, eliminate themes or variations, and especially decisions on the final groupings of variations defining each category of description. In addition to this on-going validation, at several intermediate points in analysis, preliminary results were presented to external groups for critique and feedback. Finally, upon the conclusion of analysis, the final results, the interview transcripts, and examples of coded transcript were provided to another researcher for external validation of the results. Based on the evidence and arguments provided here, and the validation of these external researchers, we argue that the results presented in the following section constitute a novel and legitimate phenomenographic result that gives meaningful and useful insight into learning assistants' approaches to teaching computational problems.

\section{RESULTS}

\section{A. Categories of description}

In phenomenographic studies, the categories of description are formed by looking across the themes identified in the data, seeking to identify groupings of variations that describe a cohesive way to experience the phenomenon of interest $[40,43,75,76]$. Four categories of description capturing the differences in learning assistants' approaches to teaching computational problems were developed based on our data. They are summarized in Table XI based on the variations that compose them, and are described in detail in this section. In each section, we provide an exemplar statement of each of the variations within each of the four themes that the category of description is characterized by. It is important to note that in a phenomenographic analysis, it is not expected that individual statements unambiguously capture or fit within a category of description. Instead, individual statements are representative of a variation within a theme. The categories of description arise from considering the emergent themes and variations as a whole, and identifying coherent sets of variations that describe ways individuals may experience the phenomenon. Therefore, in the sections following, we present statements exemplifying each variation within each theme and discuss the ways in which the statements demonstrate those variations, then we describe how the variations as a set form a coherent approach to teaching computation for each category of description.

\section{Programming focus}

The programming focus category is based around an emphasis on computation as the act of entering code. There

TABLE XI. Final categories of description. The programming focus treats the computational problems as a way to develop students' abilities to write code. The learning physics via computation focus treats the computational problems primarily as a means for learning physics concepts. The computation as a tool focus treats the computational problems as a way to help students understand the value of computation in modeling and solving problems. The shifting perceptions of learning focus treats the computational problems as opportunities to develop students' understandings of their own learning.

\begin{tabular}{l|llll}
\hline \hline Category of description & Utility of computation & Teaching outcome & Characteristic to moderate & Teaching strategy \\
\hline Programming focus & $\begin{array}{c}\text { Programming is an } \\
\text { important skill }\end{array}$ & Programming skills & Student work pace & $\begin{array}{c}\text { Focus on navigating } \\
\text { programming errors }\end{array}$ \\
\hline $\begin{array}{l}\text { Learning physics via } \\
\text { computation focus }\end{array}$ & $\begin{array}{c}\text { Computation aids } \\
\text { content learning }\end{array}$ & $\begin{array}{c}\text { Physics-code } \\
\text { connection }\end{array}$ & Impact of course design & $\begin{array}{c}\text { Leverage affordances of } \\
\text { computational problems }\end{array}$ \\
\hline $\begin{array}{l}\text { Computation as } \\
\text { a tool focus }\end{array}$ & $\begin{array}{c}\text { Computation makes } \\
\text { difficult problems easier }\end{array}$ & $\begin{array}{c}\text { Capabilities of } \\
\text { computation }\end{array}$ & $\begin{array}{c}\text { Student attention } \\
\text { to programming details }\end{array}$ & $\begin{array}{c}\text { Encourage reflection } \\
\text { on coding }\end{array}$ \\
\hline $\begin{array}{l}\text { Shifting perceptions of } \\
\text { learning focus }\end{array}$ & $\begin{array}{c}\text { Computation offers space } \\
\text { for broader skills }\end{array}$ & $\begin{array}{c}\text { A new approach } \\
\text { to learning }\end{array}$ & Student attitudes & Leverage collaboration \\
\hline \hline
\end{tabular}


is little reflection on how computation may be used in teaching or science, rather it is treated as a valuable but unconnected skill.

In the utility of computation theme, it is characterized by the belief that programming is an important skill to have in today's society, with very little elaboration or explicit reflection on why this is. For example, one learning assistant said,

[Programming] has been really helpful in a lot of my different classes, and then also in my internship this last summer, just like as an engineering person in general. That's one thing that I try and stress to the students, is it's like, "Okay, you might think that you're never going to use this, but it's actually so helpful if you do know how to use even just a small portion of it."

In this quote, the learning assistant describes how she tries to convey to her students that programming is helpful, noting that she has used it in multiple contexts. She discusses how she has used it inside and outside of the classroom, and references her background as an engineer. She does not elaborate on its importance in her learning or work, however, and she does not describe how or why it is helpful. Instead, she only states that students are likely to encounter it in other situations and that it can help them. This lack of reflection on how computation is helpful and relevant is an example of a learning assistant expressing a perception that the utility of computation is simply that programming is an important skill.

In the teaching outcome theme, the programming focus is characterized by an emphasis on programming skills. That is, the learning assistant desires their students to gain an understanding of how to carry out programming tasks. One learning assistant said,

If it's something where they added an object, or they were talking about an object, or coded in an object in their calculation loop, but never defined that object, then that's a place where it's like, "Okay, let's kind of go through this more line by line. What is this line telling us? Okay, where else does that object show up in the code? Wait, it doesn't show up anywhere else? We might need to address that." Because that is an understanding thing where they need to understand that they have to define something in the code before they can do anything to that object. You can't do something to an object that you don't have.

In this quote, the learning assistant discusses students facing an error resulting from referencing an object that they had not yet defined in their code, and states that is an error that she will intentionally target with her teaching. She goes on to say that she does this because the students "need to understand" the process of defining and calling objects in programming. Expressing a belief that her teaching should result in students knowing how to carry out elements of programming such as this indicates that programming skills are her desired teaching outcome.

In the characteristic to moderate theme, the programming focus is characterized by student work pace. When moderating this characteristic, learning assistants attend to their students' rate of progress, seeking to ensure that students reach the end of the problem by the end of class. An example of this is given by a learning assistant who said,

I might let them just mess with it for awhile. But it's sort of a time balance thing. So I've done these problems so many times, I know where they should be at certain times to make sure they finish, and so I usually let them mess with it until I think, Okay, it's halfway through, they should be at this point. I'm gonna try to redirect them back to where they should be.

With this quote, the learning assistant indicates that regardless of the exploration she'll sometimes allow her students to do, she will take steps to ensure that they are able to finish the problem in the allotted time. She explicitly comments on using particular time markers to check on where students should be at different points in the class session. This emphasis on making sure students complete the problem indicates that she moderates students' work pace.

In the teaching strategy theme, the programming focus is characterized by a focus on navigating programming errors. With this strategy, learning assistants focus their teaching on helping students identify and overcome programming errors in the traditional sense. That is, mistakes in their code that cause it not to function. One learning assistant employing this strategy stated,

Most of the time, I just teach them how to do it because it's usually when they've just like edited like one line of code, and then it's like, "Oh, we have the tabbing error." I'll just be like, "Here's how you solve that: Highlight, and then do the thing, and then, yay, it's good." Then they'll be like, "Okay. Cool. Now I know how to do this in the future."

In this quote, the learning assistant describes a common error the students encounter: problems with their indentation. VPython is a programming language that attends to white space, like tabs and spaces, and so when students incorrectly tab sections of their code, it can cause the code to stop working as they intend. This learning assistant explains that she tailors her teaching to this fact by preemptively instructing students on how to resolve that error. This emphasis on helping students handle errors of this nature demonstrates a teaching strategy that is focused on navigating programming errors. 
When considered together, one can see how these variations come together to form a cohesive approach to teaching computational problems, and one that is focused on a narrow view of programming. With the belief that computation is essentially entering programming syntax, it follows that a learning assistant's desired teaching outcome would be those sorts of programming skills. Similarly, it follows that a learning assistant with this approach would employ a teaching strategy focused on navigating programming errors, because those errors represent the fundamental obstacles of computation when one views computation to be correctly entering code. The programming focus corresponds to a belief that the utility of computation is simply that programming is an important skill. This aligns with a narrow understanding of what programming is, because without understanding there to be deeper connections between computation and science or learning, the usefulness of computation in P Cubed would simply be that students learn how to program. Finally, this approach is completed by a learning assistant moderating the pace at which their students progress through the problem. This corresponds to a programming focus because again, without a reflection on computation as a pedagogical tool or a problem-solving tool, and with programming being the act of entering code, the "game" that students must play on computational days becomes merely to get properly working code. With this belief in mind, it follows that a learning assistant would want to ensure that their students complete the problem and arrive at a correct solution. All four of these variations therefore come together to illustrate an approach to teaching computational problems characterized by a programming focus.

\section{Learning physics via computation focus}

The learning physics via computation focus is characterized by an emphasis on the computational problems providing a pedagogical tool that learning assistants may leverage in their teaching. Computation is perceived primarily as useful in the classroom to help students learn concepts.

In the utility of computation theme, the learning physics via computation focus is characterized by the belief that the value of computational problems is that they aid students' content learning. One learning assistant expressing this belief said,

The students get to see it represented so it's kind of like a reward almost for writing out the code. They think if I do this it changes this and it's beneficial to see how ... For example, we did a problem with drag. So, it's good to see how drag affects this and if we increase the coefficient it'll do this and this. It's a good way they can input information and immediately see the results of how the physics is applied.
In this quote, the learning assistant expresses that he believes the usefulness of the computational problems to be their ability to help students better understand the concepts. Specifically, he discusses how students can use the immediate feedback that computation can provide as a means to see the impact of the different physics concepts they are learning, in this case, drag. This type of emphasis indicates a belief in the utility of computation being that it can aid students' content learning.

In the teaching outcome theme, the learning physics via computation focus is characterized by an emphasis on the physics-code connection. This refers to a desire for students to see and understand how the code and visualizations involved in computation relate to the physics concepts highlighted in the course. In one example of this teaching outcome, a learning assistant said,

Actually understanding what you're coding and making sure you can tie it back to the physics. Like I said when you do the position update formula, you should be able to understand that comes from this kinematic equation. You should understand how it relates and how it should affect it.

In this quote, the learning assistant describes what she wants her students to learn from the computational problems. She discusses that the students should be able to understand how particular lines of codes, like the position update formula, relate back to the physics equations they are familiar with in algebraic form. With this, she expresses that she wishes her students to gain an understanding of the physics-code connection.

In the characteristic to moderate theme, the learning physics via computation focus is characterized by a focus on the impact of course design. Moderating this characteristic means attending to the particularities of the way $\mathrm{P}$ Cubed is taught and incorporates computation, and seeking to minimize the negative impact of their limitations. Examples include the fact that students must share one laptop, that not all necessary information is always provided in the problem statements, and the availability of the four quadrants whiteboard for work organization. A learning assistant discussed this, saying,

We have to consider who's taking over the group, like typing in by themselves, or maybe if somebody ... Like, if people have taken turns, but somebody hasn't typed in yet, then we do have to take into account that the code is something they should work on specifically, like working together with the code.

In this quote, she discusses the impact of students needing to share a single computer while solving the computational problems, which require code to be entered into the computer. She notes how individuals will sometimes dominate a group and do all the coding, and how 
other individuals may never get a turn to enter the code themselves, and how that dynamic is something learning assistants must monitor and address in their teaching on the computation days. Thus in this quote, she expresses that she moderates the impact of course design on computational days.

In the teaching strategy theme, the learning physics via computation focus is characterized by leveraging the affordances of computational problems. This refers to a learning assistant utilizing aspects unique to computation days in their teaching. An example of leveraging such an aspect is discussed by a learning assistant who said,

I'll be like, "it's acting this way, why is it acting that way?" And when the students realize that, that's not possible, I'll start questioning things that they're missing. And if they see what they're missing, then they try to add that into the problem. This, once again, goes into pseudo code, because if they see what they're missing, I usually tell them to write it out first, so that they don't make those errors.

In this quote, the learning assistant describes how he will encourage his students to write pseudocode when they encounter difficulties on computation days. By pseudocode, he is referring to an approximation of what the desired code is, not yet worrying about entirely correct syntax. He explains that he will have students write this almost code out on their whiteboard when they are having trouble getting it to work in the computer. As pseudocode is an attempt at writing information in a way the computer will ultimately be able to understand, it is a construct uniquely relevant on computation days. In this way, this learning assistant discusses employing a teaching strategy which leverages the affordances of the computational problems.

Considering these four variations together, there is a coherent approach to teaching computational problems that emerges that is centered around a focus on computation as a means of learning physics. With this emphasis on computational problems as a pedagogical tool, it is consistent that a learning assistant would view the utility of computation to be its ability to aid students' content learning. It also follows that a learning assistant with this approach would employ teaching strategies which leverage the capabilities of computation, given that they focus on computational problems as a means for students to learn physics concepts. The desired teaching outcome in the learning physics via computation focus is an understanding of the physics-code connection, that is, an understanding of exactly how the computational work relates to the physics concepts being taught. It is unsurprising that a learning assistant with this approach would want their students to understand the physics-code connection, because they view the computational problems as fundamentally being a venue for students to learn the physics concepts. With that view, it is understandable that they would want their students to explicitly understand how the code and visualizations present in the computational problems are connected to the physics. Finally, the characteristic moderated in this approach is the impact of course design based. Because the learning physics via computation focus as a whole is very focused on computation as a pedagogical tool and is grounded in the context of education, it is consistent that a learning assistant with this approach would pay attention to the classroom in which they are teaching, particularly the limitations and affordances that it presents, resulting in a focus on moderating the impact of the course's design in their teaching. This combination of four variations together characterize an approach to teaching computational problems that focuses on students learning physics via computation.

\section{Computation as a tool focus}

The computation as a tool focus is an approach to teaching computational problems that emphasizes the usefulness of computation as a method of approaching problems. Computation is treated as a tool that is valuable in mathematical and scientific problem solving.

In this utility of computation theme, the computation as a tool focus is characterized by the belief that computation makes difficult problems easier. It is a perception that computation provides affordances that are an important part of modeling or solving complex problems. One learning assistant expressing this belief said,

What makes the computer good is that it involves ... Like a big thing is the time step. The smaller you make that time step, the more accurate everything is. If you wanted to write and draw that out, you could, but you'd have to use a grid system. You could. I don't know how much that would actually help or prove.

In this quote, the learning assistant discusses that computers can be used to carry out iterative numerical calculations, and that it is simple to control how many iterations the computer calculates by modifying the time step (the interval between each calculation). He contrasts that with how difficult it would be to do this analytically. He explicitly identifies the ability to do an increasing number of calculations easily as "what makes the computer good." By articulating and emphasizing how computation can be utilized to carry out difficult calculations, he indicates a belief that the utility of computation is that it makes difficult problems easier.

In the teaching outcome theme, the computation as a tool focus is characterized by an emphasis on students appreciating the capabilities of computation. With this outcome, a learning assistant wants their students to understand the benefits that computation provides. This is closely tied to the aforementioned belief that the utility of computation is 
that it makes difficult problems easier. While computation making difficult problems easier describes what the learning assistant perceives the usefulness of computation to be, the capabilities of computation describes what they want their students to takeaway from their experience with computation. An example of this appears from a learning assistant who said,

The computation is important, it's an important skill, but understanding how the computation is helping them solve physics is always what I think about the most. The computer is solving all these equations and updating all this stuff, so what does that mean on pen and paper, and what does that mean for the physics?

In this quote, the learning assistant discusses how she focuses on how computation helps students solve the physics problems. She explicitly states how this is the important part of computation, and how it is more important than just the skill of being able to program. She expresses that what she wants students to understand how exactly it is that the computer is helping them. In this way, she suggests that the desired teaching outcome she has for her students is that they gain an understanding of the capabilities of computation.

In the characteristic to moderate theme, the computation as a tool focus is characterized by student attention to programming details. This means an attention to preventing students from becoming too caught up in the details of syntax and coding, to the detriment of their understanding the larger picture of computation. One learning assistant moderating this characteristic said,

When it's just a spacing error that they've been working on for ten minutes, that's not super productive. And hopefully they just call me over when that happens, but I'm sure there are times when they're just messing with an error for 15 minutes, or ... probably not that long. Hopefully not to that point, but where they still have no idea how to fix it, and it's not helping them learn the physics, and it's not really helping them learn coding, 'cause they're just trying to find this tiny error.

In this quote, the learning assistant describes a difficulty students often have during the computational problems: getting their code properly spaced and tabbed. She discusses how spending too much time on this sort of error is not a good use of the students' time, explicitly noting that it does not help them learn the physics concepts or coding. She also expresses that she hopes she is able to intervene before the students waste too much time on a task like this. By treating the navigation of this sort of error as not aligned with learning coding and by indicating that she does not want students to spend time on these types of issues, she indicates a desire for students to not focus on unimportant programming details to the neglect of other computational skills. In this way, she expresses that student attention to programming details is a characteristic she moderates.

In the teaching strategy theme, the computation as a tool focus is characterized by encouraging reflection on coding. This means prompting students to think more deeply about how their code functions and how they can best utilize the program. A learning assistant discussing this strategy said,

I would get them to focus on talking about how the code is supposed to be iterative. It's supposed to do the calculations for you. You shouldn't be doing the calculations outside of it and inputting numbers because then you're constraining the code to specific parameters, [but] the code is very versatile. You're supposed to be able to just hit run, change things to see how changing the variables affects the system.

In this quote, the learning assistant discusses how he will encourage his students to talk about what the code is able to do, such as carrying out calculations and allowing one to keep parameters variable. He emphasizes that the code is "very versatile" and that this should be leveraged, and he describes how he encourages his students to discuss these matters. This focus indicates a teaching strategy that is based on encouraging students to reflect on coding.

These four variations considered at once illustrate a coherent approach to teaching computational problems that is based around a focus on computation as a tool. Given a focus on computation as a tool, it follows that this teaching approach is characterized by a belief that the utility of computation is its ability to make difficult problems easier when leveraged, as this represents an example of its application as a tool. It also follows that a learning assistant with this approach would want their students to understand the capabilities of computation that make it such an important tool. In order to achieve this desired teaching outcome, it is consistent that a teaching strategy focused on encouraging reflection on coding would be employed. Prompting such reflection would facilitate students developing an appreciation for the affordances that computation provides them, and this emphasis makes sense given a focus on computation as a tool. The characteristic to moderate in this approach is student attention to programming details, which is also consistent with a belief that computation is a valuable tool. A learning assistant with this approach perceives computation to be more than simply entering syntax, instead treating computation as an important tool that can be utilized in modeling and solving difficult problems. Correspondingly, they do not wish their students to become bogged down in the details of syntax and leave with the impression that is all that computation is. Rather, they want students to gain an appreciation of the greater value of computation. In this way, these four variations come together to indicate an approach to teaching computational problems that is focused on computation as a tool. 


\section{Shifting perceptions of learning focus}

The shifting perceptions of learning focus is characterized by an emphasis on computational problems as an opportunity to affect students' beliefs about and approaches to learning. Computation is viewed as more than a pedagogical or problem-solving tool, and is instead treated as a means to impact students' ongoing ideas about how they learn and approach problems.

In the utility of computation theme, the shifting perceptions of learning focus is characterized by the belief that computation offers a space for broader skills to be developed. These skills could include how to collaborate effectively, how to think in new ways, and how to persevere through challenging problems. One learning assistant with such a belief said,

That's [the computation problems] definitely where I see them learn a lot of effective ways to work in a group or in a team, which that's a big part of this class. Going forward, they definitely will need to know how to do that.

In this quote, the learning assistant describes how she has observed that the computation days are where the students most learn how to collaborate. She goes on to state that this is an important skill for them to know beyond the course. With this, she indicates a belief that the computational problems' utility is their ability to offer students a space to develop broader skills that go beyond physics and computation.

In the teaching outcome theme, the shifting perceptions of learning focus is characterized by a new approach to learning. This refers to a desire for students to develop a new approach to their learning through the computational problems. A learning assistant with this goal for their teaching said,

I was trying to get them to see that, "Okay, if these two conditions are conflicting, then that statement will never be true, so that segment of code will never run." If it's high up, then that just stops the code. Trying to get them to think through it logically rather than just like, "Okay, well let's just type something in and see if that changes anything," so stepping back and going, "Okay, well we know that this is true, we know this, and let's just look at this from a logical physics perspective rather than a coding perspective."

In this quote, the learning assistant describes a situation in which her students' code was not running because they had entered conflicting conditions. She explains how she wanted her students to think "logically" through the code and error, rather than simply making changes arbitrarily, demonstrating a desire she had for her students to take a more intentional and methodical approach to their problem solving. This sort of focus on changing how students approach their learning and problem solving is indicative of a new approach to learning to being her intended teaching outcome.

In the characteristic to moderate theme, the shifting perceptions of learning focus is characterized by student attitudes. When moderating this characteristic, a learning assistant focuses on ensuring that students do not become too frustrated or unhappy while working on the computational problems. A learning assistant moderating this characteristic with her teaching said,

If they say something like "this is so frustrating, like I just want to give up," then you'll see them kind of start to get disengaged I guess. Like while you're doing the trial and error, usually the whole group is kind of looking at what's going on and is involved and wants to fix it and make it work. When you see them start to sort of you know, fall back and give up essentially then that's kind of where you want to make sure that you get them on the right track I guess.

In this quote, the learning assistant describes how she identifies when students have become frustrated to the point of no longer participating. She notes that at the beginning of problems, when groups are typically testing what different changes to the code do, students are generally engaged, but that as the problem progresses, frustration can lead to students becoming disengaged. She highlights that it is important to make sure that students do not get to that point of frustration. This focus on preventing students from becoming too demoralized indicates that she perceives student attitudes to be an important characteristic to moderate.

In the teaching strategy theme, the shifting perceptions of learning focus is characterized by leveraging collaboration. When employing this strategy, learning assistants capitalize on the fact that the course is a collaborative learning environment, and that students work in groups. One learning assistant discussing this teaching strategy said,

I might say something like you know, ask somebody, ask a group what they are doing and if someone responds and it looks like the other two aren't paying any attention, I might ask, "Oh, are you guys good with that?" or like "Are you guys on the same page?" or "Do these guys understand that?" or something like that to sort of let them know that they should be conversing.

In this quote, the learning assistant describes how she will ask questions of a group that are targeted at assessing if there is agreement amongst the students and if all the students understand the group's work. She explains that she does this to convey to them that they should all be discussing the problem and concepts with each other as they work. This focus on encouraging students to take advantage of the fact that they are working in groups by 
having more discussions is an example of employing a teaching strategy that leverages collaboration.

In combination, these four variations describe an approach to teaching computational problems that is focused on computation as a way to shift students' perceptions of learning. With this view of computation in mind, it follows that the desired outcome of a learning assistant's teaching would be for students to adopt a new approach to their learning from the avenue for this that computation provides. It also is consistent that a learning assistant focused on computation as a way to shift learning perceptions would believe the utility of computation to be that it provides a space for students to develop skills that are beyond content. Skills like collaboration and intentionality when problem solving are tied to how students' approach and perceive their learning, and so a learning assistant with a focus on shifting perceptions of learning would emphasis computation's utility in developing those skills. The shifting perceptions of learning focus is characterized by a teaching strategy that leverages collaboration. This strategy is also aligned with this focus because by leveraging collaboration, a learning assistant utilizes an aspect of the learning environment that is specifically designed to alter how students approach their learning and problem solving. This strategy thus implicitly addresses how students approach their learning, and continues the focus on computation as a way to shift perceptions of learning. The characteristic to moderate corresponding to this approach is student attitudes. In order to attempt to shift students' perceptions of learning through the computational problems, it is unsurprising that a learning assistant would attend to student attitudes, and in particular, make sure students did not become frustrated to the point of disengagement. If a learning assistant is focused on shifting students' perceptions of learning, it is understandable that they would believe that engagement and a positive attitude are necessities to being able to influence students in this way. Thus these four variations when considered together comprise an approach to teaching computational problems that focuses on their ability to shift students' perceptions of learning.

These four categories of description capture the variation in how the learning assistants described their approaches to teaching computational problems in this environment. As described previously, however, categories of description are only part of the results of a phenomenographic study. The categories must also be connected via some logical structure known as an outcome space $[40,43,75,76]$.

\section{B. Outcome space}

The four approaches to teaching computational problems identified in this study are connected via the outcome space shown in Fig. 1. Going from the programming focus to the shifting perceptions of learning focus, each approach represents an increasing level of alignment with the

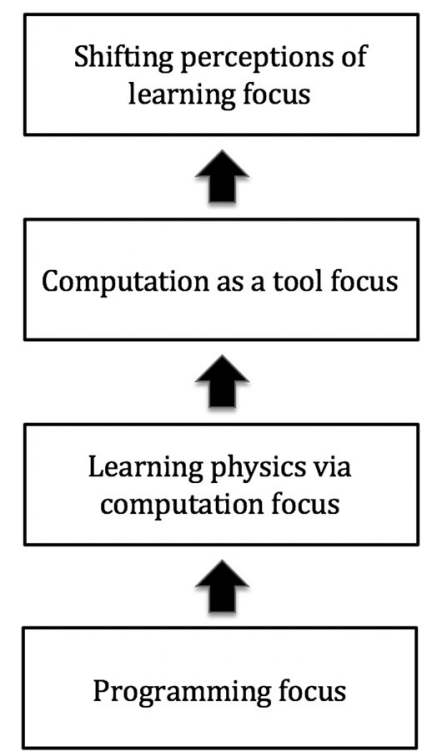

FIG. 1. Outcome space indicating the structure relating the identified learning assistant approaches to teaching computational problems.

course's goals. The designers of P-Cubed incorporated computation into the curriculum not simply to give students experience in writing code, but also with the aims of deepening students' understanding of physics, helping students come to understand the power of computational problem solving and modeling, and encouraging students to become more reflective and intentional in their problem solving and learning [19]. The teaching approaches identified in our analysis indicate varying levels of uptake regarding these course goals.

With the programming focus, computation is treated primarily as a means to learn programming skills, such as syntax and elements like loops. These skills are not framed as being connected to students' learning or their perceptions of computation or learning, and instead are treated as things that are simply good to know with little reflection on why, as indicated by a lack of substance in their discussion of computation's purpose. By neglecting to reflect in this way on what computation is and what it offers students, such an approach indicates a relatively limited understanding of the purpose and usefulness of teaching computational problems in the course, and a rather narrow goal for one's teaching that is not very well aligned with the course goals regarding computation.

In the learning physics via computation focus, the computational problems are treated as pedagogical tools. They are framed as contexts that offer particular opportunities to develop students' understandings of the physics concepts. This approach indicates reflection on the ways that the computational problems can aid students' learning beyond simply gaining programming proficiency. It demonstrates an attention to the fact that the computational problems are about physics concepts and are embedded in a 
physics course, and an intentionality about leveraging that in one's teaching. These considerations are aligned with the course goal that computation serve to deepen students' understanding of physics, and so this teaching approach is more in line with course goals than the programming focus. This approach does not expand beyond the classroom or the course's subject, however, to consider the broader value and opportunities the computational problems provide, which are also course goals.

The computation as a tool focus represents such an expanded focus, by treating the computational problems as an opportunity for students to better understand the value of computation outside of the classroom. Rather than seeing computation as a mechanism to help students understand the physics concepts that they are meant to learn in the course, the computational problems are framed as a space for students to gain an appreciation of the power of computation in solving complex problems. The computation as a tool focus goes beyond the more straightforward course goal of using computation to help students learn physics, by also attending to the more complex course goal of helping students see the value of computation more broadly. As the context of this study was a physics course, it is to some degree a given that developing students' understanding of physics is a central part of teaching the course. Because the course is designed for introductory students and does not require any computation-related prerequisites, the course is designed with the assumption that students have not had prior experiences with computation in physics, or even computation in general. In a context such as this, a learning assistant seeking to affect students' perceptions of the usefulness of computation is attending to a complex and less self-evident course goal surrounding computation. The computation as a tool focus thus reflects a greater degree of alignment with more course goals than the previous two approaches.

The shifting perceptions of learning focus represents the greatest degree of alignment with the course goals, as it treats the computational problems as a venue in which to impact students' perceptions of and approaches to their own thinking, learning, and problem solving. Rather than focusing on the classroom-style learning of physics concepts or even students' general perceptions of computation, this approach frames the computational problems as a chance to alter how students go about learning new things regardless of the context. This approach is aligned with the course's most complex goal-encouraging students to become more reflective and intentional in their problem solving and learning. This is the most fundamental goal of the course's design and one that informs all the other course goals. As such, alignment with this course goal indicates a very high degree of alignment with the course goals as a whole. Because of this, the shifting perceptions of learning focus represents the greatest alignment with course goals.
In this way, the four approaches to teaching computational problems identified through the learning assistants in this study represent an increasing degree of alignment with course goals regarding computation. Progressing up Fig. 1, each approach indicates learning assistants being better aligned with more course goals and more complex course goals surrounding computation. The approaches identified in this study and the structure relating them have connections to prior work and implications for learning assistant training and support.

\section{DISCUSSION}

There were four themes that were salient when considering the teaching approaches the learning assistants interviewed for this study took to teaching computational problems: their perceptions of the utility of computation, their intended outcome for their students, what characteristics they moderated while teaching, and the strategies they employed while teaching. Based on learning assistants' beliefs about each of these themes, we identified four approaches to teaching computational problems: a narrow focus on the act of programming, a focus on learning concepts through computation, a focus on computation's position as a valuable tool, and a focus on shifting students' perceptions of their own learning. Each of these approaches represents a varying degree of alignment with goals of the course design of $\mathrm{P}$ Cubed. The approaches to teaching computational problems that we identified are therefore not entirely surprising, as they suggest learning assistants are taking up different goals of the course to different degrees. While one designer of the course is able to message the course goals surrounding computation by co-leading learning assistant training each semester and by attending weekly postclass meetings, the course is taught by varying faculty members and graduate teaching assistants, who also impact the messages learning assistants receive regarding teaching in the course. Additionally, as described previously, the learning assistants interviewed for this study came from diverse majors and backgrounds with respect to computation and teaching, and also had varying levels of experience teaching in P Cubed. This led us to believe we would uncover meaningful variations in their approaches, and the development of the categories of description and outcome space presented here confirms that this was the case.

After developing these results, the interview of each learning assistant was considered individually, in order to identify with which approach to teaching each was most aligned. An individual's transcript was examined for comments regarding each theme, and for which variation within each theme these comments reflected. Based on the variations an individual most reflected in each theme, they were assigned to the teaching approach that was most aligned with their combination of variations. Because the teaching approaches identified in this study were not 
developed with the aim of unambiguously categorizing these learning assistants, most individuals did not align perfectly with a single teaching approach, and instead expressed elements of multiple teaching approaches. This is demonstrated in Tables XII and XIII, which provide examples of the analysis used to categorize the teaching approach of two learning assistants. The Tables indicate how many statements the learning assistants made aligned with each teaching approach, within each theme. In Table XII, it can be seen that in three of the four themes, Kendra made statements that spanned multiple teaching approaches. While learning assistants typically made statements across multiple teaching approaches, in order to ascertain the teaching approaches the learning assistants were most aligned with, they were assigned to a teaching approach based on the one that best accounted for the variations they expressed in each theme. The results of this process are given in Table XIV, which shows the teaching approaches that each learning assistant aligned with along each theme and which teaching approach each aligned with most overall. Table XV summarizes these results across individuals and shows the number of learning assistants aligned most with each teaching approach, and the number of semesters that each had taught in P Cubed. The process of sorting learning assistants into categories described here is one way of utilizing our main finding: the approaches to teaching computational physics problems. It is important to frame this sorting process with the acknowledgement that learning assistants may be transitioning between approaches as they gain more experience in teaching the class, and again, that the teaching approaches identified here are not intended to unambiguously capture the experience of each learning assistant. Limited weight should then be placed on this sorting via counting, and it should in no way be viewed as part of our phenomenographic methodology. The results of sorting the learning assistants into their most aligned teaching approaches is not a primary result of this research, and was carried out to aid in the development of future research questions when considered with other data from the interviews, and to give some insight into the degrees to which these learning assistants took up aspects of the different teaching approaches.

The results of this sorting are interesting for several reasons. First, the majority of the learning assistants take either the learning physics via computation focus or the shifting perceptions of learning focus. These two approaches have less explicit focus on computation than the programming focus and computation as a tool focus themes, perhaps indicating that learning assistants are likely to view the computation as secondary to learning, whether it be conceptual learning or reflection on learning. This could also be an effect of the fact that the majority of the problems in the course are analytic rather than computational. It is also notable that there does not appear to be a correlation between amount of experience and teaching approach, though one might expect approaches more aligned with course goals to develop over time. The two

TABLE XII. Analysis of Kendra's teaching approach. The numbers indicate the amount of statements Kendra made aligned with each teaching approach, within each theme. For example, Kendra made five statements total within the teaching outcome theme. One was aligned with a programming focus, one was aligned with a computation as a tool focus, and three were aligned with a learning physics via computation focus.

\begin{tabular}{|c|c|c|c|c|}
\hline \multirow[b]{2}{*}{ Teaching approach } & \multicolumn{4}{|c|}{ Theme } \\
\hline & Utility of computation & Teaching outcome & Characteristic to moderate & Teaching strategy \\
\hline Programming focus & 0 & 1 & 0 & 4 \\
\hline Learning physics via computation focus & 0 & 3 & 5 & 0 \\
\hline Computation as a tool focus & 2 & 1 & 2 & 1 \\
\hline Shifting perceptions of learning focus & 0 & 0 & 0 & 1 \\
\hline
\end{tabular}

TABLE XIII. Analysis of Penelope's teaching approach. The numbers indicate the amount of statements Penelope made aligned with each teaching approach, within each theme. For example, Penelope made five statements total within the characteristic to moderate theme. One was aligned with a learning physics via computation focus, and four were aligned with a shifting perceptions of learning focus.

\begin{tabular}{|c|c|c|c|c|}
\hline \multirow[b]{2}{*}{ Teaching approach } & \multicolumn{4}{|c|}{ Theme } \\
\hline & Utility of computation & Teaching outcome & Characteristic to moderate & Teaching strategy \\
\hline Programming focus & 0 & 0 & 0 & 0 \\
\hline Learning physics via computation focus & 1 & 0 & 1 & 1 \\
\hline Computation as a tool focus & 0 & 0 & 0 & 1 \\
\hline Shifting perceptions of learning focus & 2 & 2 & 4 & 3 \\
\hline
\end{tabular}


TABLE XIV. Description of each learning assistant's teaching approach. Columns 2-5 indicate with which teaching approach the variation they displayed in each theme was associated. For example, in the utility of computation theme, the majority of Alicia's comments fell under the computation aids content learning variation. This is the variation associated with the teaching approach of learning physics via computation focus, and so she is indicated as being aligned with learning physics via computation focus in the utility of computation theme. Column 6 indicates which teaching approach each learning assistant is most aligned with overall, given their alignment along each of the four themes. *Seamus did not discuss any of the teaching outcome variations used in our analysis, and so he is given no assignment along that theme.

\begin{tabular}{|c|c|c|c|c|c|}
\hline Pseudonym & $\begin{array}{l}\text { Utility of } \\
\text { computation }\end{array}$ & $\begin{array}{l}\text { Teaching } \\
\text { outcome }\end{array}$ & $\begin{array}{l}\text { Characteristic } \\
\text { to moderate }\end{array}$ & $\begin{array}{l}\text { Teaching } \\
\text { strategy }\end{array}$ & $\begin{array}{l}\text { Most aligned } \\
\text { teaching approach }\end{array}$ \\
\hline Alicia & $\begin{array}{l}\text { Learning physics via } \\
\text { computation focus }\end{array}$ & $\begin{array}{c}\text { Shifting perceptions } \\
\text { of learning focus }\end{array}$ & $\begin{array}{c}\text { Shifting perceptions } \\
\text { of learning focus }\end{array}$ & $\begin{array}{c}\text { Shifting perceptions } \\
\text { of learning focus }\end{array}$ & $\begin{array}{c}\text { Shifting perceptions } \\
\text { of learning focus }\end{array}$ \\
\hline Angelina & Programming focus & $\begin{array}{l}\text { Shifting perceptions } \\
\text { of learning focus }\end{array}$ & $\begin{array}{l}\text { Shifting perceptions } \\
\text { of learning focus }\end{array}$ & $\begin{array}{l}\text { Learning physics } \\
\text { via computation } \\
\text { focus }\end{array}$ & $\begin{array}{c}\text { Shifting perceptions } \\
\text { of learning focus }\end{array}$ \\
\hline Arthur & $\begin{array}{l}\text { Computation } \\
\text { as a tool focus }\end{array}$ & $\begin{array}{c}\text { Shifting perceptions } \\
\text { of learning focus }\end{array}$ & $\begin{array}{l}\text { Computation as } \\
\text { a tool focus }\end{array}$ & $\begin{array}{l}\text { Computation as } \\
\text { a tool focus }\end{array}$ & $\begin{array}{l}\text { Computation as } \\
\text { a tool focus }\end{array}$ \\
\hline Dean & $\begin{array}{l}\text { Learning physics via } \\
\text { computation focus }\end{array}$ & Programming focus & $\begin{array}{l}\text { Shifting perceptions } \\
\text { of learning focus }\end{array}$ & $\begin{array}{l}\text { Learning physics } \\
\text { via computation } \\
\text { focus }\end{array}$ & $\begin{array}{l}\text { Learning physics } \\
\text { via computation } \\
\text { focus }\end{array}$ \\
\hline Harry & $\begin{array}{l}\text { Shifting perceptions } \\
\text { of learning focus }\end{array}$ & $\begin{array}{l}\text { Shifting perceptions } \\
\text { of learning focus }\end{array}$ & $\begin{array}{l}\text { Computation as } \\
\text { a tool focus }\end{array}$ & $\begin{array}{l}\text { Shifting perceptions } \\
\text { of learning focus }\end{array}$ & $\begin{array}{c}\text { Shifting perceptions } \\
\text { of learning focus }\end{array}$ \\
\hline Kendra & $\begin{array}{l}\text { Computation as } \\
\text { a tool focus }\end{array}$ & $\begin{array}{l}\text { Learning physics } \\
\text { via computation focus }\end{array}$ & $\begin{array}{l}\text { Learning physics via } \\
\text { computation focus }\end{array}$ & Programming focus & $\begin{array}{l}\text { Learning physics } \\
\text { via computation } \\
\text { focus }\end{array}$ \\
\hline Lavender & $\begin{array}{l}\text { Learning physics via } \\
\text { computation focus }\end{array}$ & $\begin{array}{l}\text { Shifting perceptions } \\
\text { of learning focus }\end{array}$ & $\begin{array}{l}\text { Computation } \\
\text { as a tool focus }\end{array}$ & $\begin{array}{l}\text { Shifting perceptions } \\
\text { of learning focus }\end{array}$ & $\begin{array}{c}\text { Shifting perceptions } \\
\text { of learning focus }\end{array}$ \\
\hline Molly & Programming focus & $\begin{array}{l}\text { Learning physics via } \\
\text { computation focus }\end{array}$ & Programming focus & $\begin{array}{l}\text { Computation } \\
\text { as a tool focus }\end{array}$ & Programming focus \\
\hline Penelope & $\begin{array}{l}\text { Shifting perceptions } \\
\text { of learning focus }\end{array}$ & $\begin{array}{c}\text { Shifting perceptions } \\
\text { of learning focus }\end{array}$ & $\begin{array}{c}\text { Shifting perceptions } \\
\text { of learning focus }\end{array}$ & $\begin{array}{c}\text { Shifting perceptions } \\
\text { of learning focus }\end{array}$ & $\begin{array}{c}\text { Shifting perceptions } \\
\text { of learning focus }\end{array}$ \\
\hline Rita & $\begin{array}{l}\text { Learning physics } \\
\text { via computation focus }\end{array}$ & $\begin{array}{l}\text { Learning physics via } \\
\text { computation focus }\end{array}$ & Programming focus & $\begin{array}{l}\text { Learning physics } \\
\text { via computation focus }\end{array}$ & $\begin{array}{l}\text { Learning physics } \\
\text { via computation } \\
\text { focus }\end{array}$ \\
\hline Ronald & $\begin{array}{l}\text { Learning physics } \\
\text { via computation focus }\end{array}$ & $\begin{array}{c}\text { Shifting perceptions } \\
\text { of learning focus }\end{array}$ & $\begin{array}{c}\text { Shifting perceptions } \\
\text { of learning focus }\end{array}$ & $\begin{array}{c}\text { Shifting perceptions } \\
\text { of learning focus }\end{array}$ & $\begin{array}{c}\text { Shifting perceptions } \\
\text { of learning focus }\end{array}$ \\
\hline Seamus & $\begin{array}{l}\text { Learning physics via } \\
\text { computation focus }\end{array}$ & NA* & $\begin{array}{l}\text { Learning physics via } \\
\text { computation focus }\end{array}$ & $\begin{array}{l}\text { Shifting perceptions } \\
\text { of learning focus }\end{array}$ & $\begin{array}{l}\text { Learning physics } \\
\text { via computation } \\
\text { focus }\end{array}$ \\
\hline
\end{tabular}

most populated approaches had comparable distributions of experience, and the only learning assistant with the least aligned approach was one of the most experienced, with five semesters of experience. This result suggests that it is unclear what effect experience in the classroom has on the teaching approaches that learning assistants take. Investigating the teaching approaches that learning assistants discuss over the course of their tenure, or before and after training could shed light on what causes shifts in their approaches. Using the teaching approaches identified here as a lens to consider the changes or lack of changes in their approaches could also inform for how we train and support the development of our learning assistants as teachers. For example, the presemester training currently does not discuss the computational problems or their purpose explicitly, and modifying the training to address this could encourage learning assistants to adopt the approaches better aligned with course goals. Doing this could ensure that the intended course goals and messages regarding computation are reaching the students. As it stands, the diversity of approaches taken by the learning assistants suggests that the training they undergo together is not sufficient to ensure that they take up the course's intended goals surrounding computation. It could be that the differences in their experiences as students in the course, which are of significantly longer duration than the learning assistant 
TABLE XV. Number of learning assistants most aligned with each teaching approach and their experience levels.

\begin{tabular}{lcc}
\hline \hline Teaching approach & Number & Experience levels \\
\hline Programming focus & 1 & 5 semesters \\
Learning physics via & 4 & $1,2,3$, and 3 semesters \\
$\quad$ computation focus & & \\
Computation as a tool focus & 1 & 6 semesters \\
$\begin{array}{l}\text { Shifting perceptions } \\
\quad \text { of learning focus }\end{array}$ & 6 & $\begin{array}{l}1,2,2,4,4, \text { and } \\
\text { semesters }\end{array}$ \\
\hline \hline
\end{tabular}

training, are having a greater impact on their teaching approaches than the training. This possibility could be investigated further by conducting interviews with new learning assistants before their training to see if there are any differences in the distribution of their approaches to the distribution of those taken by the trained and experienced learning assistants interviewed here.

In addition to the learning assistants' amount of experience, we also investigated if there were correlations between the approaches learning assistants took and their major, class rank, or gender. After grouping the learning assistants by each of these demographic characteristics in turn and looking for trends in the approaches they took, similar to the process applied in Table XV, we identified no clear correlations. Tables of these data are omitted in order to protect the identity of our participants, given the small sample size and potential for identifying individuals.

It is worth highlighting that the results presented here are based on the experiences of learning assistants, and not the graduate teaching assistants and faculty members who also teach in P Cubed. A focus on learning assistants gives us insight into how the majority of the teaching team approaches teaching computational problems (learning assistants comprise $12 / 15$ of the individuals teaching in the classroom), and therefore a better understanding of the teaching population with the most broad influence over the experiences students will have with computation. Analyzing the experiences of learning assistants also helps us better understand how individuals who experience a course as a student go on to engage in it as a teacher. Indeed, we found that despite the learning assistants having shared experiences as students in the course, there is a high degree of variation in how learning assistants take up course goals. This result is important for considering how to train and support learning assistants. Finally, learning assistants are in general an understudied population when compared to faculty members and graduate teaching assistants, while learning assistants are simultaneously being incorporated into more and more courses. Examining their approaches to teaching thus adds to an essential body of literature on understanding of how learning assistants operate within the classroom.

The approaches to teaching presented here have connections to previous research on approaches to learning, and previous research on instructors' beliefs and practices in teaching [31,65,70,89-92]. Several studies in particular have notable connections to our results. In their work on learning assistants' beliefs about teaching and learning, Gray et al. examined a context that did not involve computational problems, but their results have a relationship with ours nonetheless. They found that learning assistants may perceive themselves as occupying four different roles: facilitating physics content, facilitating students' sense-making, shaping the learning environment, and professional growth [31]. The first two roles identified in their work are aligned with the learning physics via computation focus, in that they frame physics content in some way as the primary goal. Their identification of two versions of a focus on physics content could be related their context, in which students work primarily on tutorials. Tutorials are structured and ask direct questions, which could prompt learning assistants to engage in simple content transmission so that students arrive at those answers. The problem-based learning style of P Cubed might make such an approach difficult to implement, since students must navigate complex problems that may not have clearly defined questions. As a result, it is possible the learning physics via computation focus identified here is more comparable to their facilitating students' sensemaking role. The shaping the learning environment role they identified may be related to the shifting perceptions of learning focus, as both contain a focus on the collaborative nature of the learning environments. In the shaping the learning environment role, however, it is not clear if the learning assistants want their students to adopt a new learning style as in the shifting perceptions of learning focus, or if they simply see themselves as a moderator of group dynamics. The professional growth role identified by Gray et al. did not appear in our data. This could be because we did not probe this area of their experiences in our interviews, and it could also be because the $\mathrm{P}$ Cubed learning assistant model does not explicitly emphasize its role in the development of new teachers in the way that the University of Colorado Boulder (where Gray et al. conducted their work) learning assistant model does [27].

Our results are also related to the work by Bruce et al. on students' experiences learning programming. Although they focused on student experiences, and the work presented here focuses on instructor approaches, parallels can be seen between the results of each. In their phenomenographic study, Bruce et al. identified five ways that students may experience the process of learning to program: following (focusing on getting through an activity), coding (focusing on learning to write code), understanding and integrating (focusing on using a conceptual understanding of programming), problem solving (focusing on programming in the context of solving problems), and participating or enculturation (focusing on developing an identity as a programmer and/or an affinity with the culture of programming. They argue that each of these ways of 
experiencing learning to program represents a student taking on a more expansive view of programming [65]. The results of Bruce et al. are related to ours in several ways. Both the "following" and "coding" categories are related to the programming focus, as they all focus on simply accomplishing the computational task and gaining some degree of proficiency with writing code. The "problem solving" category is aligned with the computation as a tool focus, as both treat programming as a way to approach problems. Because their work was carried out in a context explicitly teaching programming, while ours was carried out in a physics course which incorporated programming, other connections between the results are less clear. The "understanding and integrating" category may be related to the learning physics via computation focus as both focus on gaining a conceptual understanding of the course's content, whether it be programming itself or physics. The "participating or enculturation" category may be related to the shifting perceptions of learning focus, as both describe a broader change in how students perceive their work, gaining an understanding of programming as a community in the case of the former, and gaining an understanding of a new approach to learning in the latter. While the relationship between our results and those of Bruce et al. is not entirely clear, these connections could provide some insight into how learning assistants come to their teaching approaches. Because learning assistants experience the class first as students themselves, and because little time passes between their experiences as students and their experiences as instructors, it could be that their student experiences are having a significant impact on their teaching approaches.

The results presented here are closely related to the phenomenographic study by Magana et al. on instructors' intended outcomes when teaching computation. They found eight different intended outcomes that instructors may have in incorporating computation into their courses: to become aware of the role of computation in science, to make measurements, to find causal relationships in models, to test models, to validate results, to use computational techniques, to predict behavior, and to discriminate among possible models. They further argued that these eight intended outcomes represent increasingly higher order levels of thinking [70]. It is difficult to match these to our results precisely, since their results describe desired outcomes, which is just one of the four themes that comprise each of the teaching approaches identified in our work. Despite this, there are relationships that can be uncovered. The "become aware of the role of computation in science" outcome is aligned with the computation as a tool focus, as both emphasize students gaining an understanding of the usefulness of computation. The "use computational techniques" outcome is aligned with the programming focus in that both emphasize students gaining programming skills. The relationship between remaining outcomes identified by Magana et al. and the teaching approaches we identified is unclear. It could be that the instructors they interviewed have these intended outcomes towards the goal of students better understanding the concepts of their scientific discipline, which could align with the learning physics via computation focus. It could also be that they have these intended outcomes towards the goal of showing students specific computational capabilities, which could align with the computation as a tool focus. None of the intended outcomes identified by Magana et al. appear to have an explicit relationship to the shifting perceptions of learning focus. It is also worth noting that their hierarchy of instructors' intended outcomes based on higher orders of thinking does not align with our hierarchy based on increasing levels of alignment with course goals. For example, while they position "become aware of the role of computation in science" as the lowest order level of thinking, we position the computation as a tool focus as one of the approaches to teaching better aligned with complex course goals. This may be a result of differences in how the instructors Magana et al. interviewed and the course designers of P-Cubed in our context frame this goal.

There are limitations to our results. The approaches to teaching computation identified here are based on learning assistants teaching in a problem-based course, and one that puts significant time and effort into their training. Additionally, the course implements computational problems in an intentional way and has particular goals for students' engagement with those problems. This likely affected the experiences the learning assistants discussed and the approaches to teaching that they adopted. Indeed, the approaches identified here are fundamentally related to the course's intended goals, and we would expect a new set of learning assistants from this course to discuss similar themes due to their shared experiences in training and in the classroom. It is possible that in a course emphasizing different goals or implementing computation differently, different teaching approaches may be identified. Michigan State University now offers a degree in computational mathematics, science, and engineering (CMSE), and it is possible that a learning assistant in a course in that program would have unique ideas about the purpose of computation instruction in a science course. While the approaches to teaching identified here may not describe the approaches of learning assistants in such a context, our results still provide a framework that would be useful when examining this new environment. For example, it would be interesting to compare the beliefs and teaching approaches of a CMSE learning assistant to the approaches presented here, and to investigate what may have resulted in their differences and similarities.

Focusing on learning assistants and not graduate teaching assistants and faculty members also results in some limitations. Graduate teaching assistants and faculty members are also essential components of the teaching team, and are perhaps populations that are more commonly used 
to teach computation at other institutions. It is possible that graduate teaching assistants and faculty members would have different perspectives on teaching computation given their different levels of experience with physics, computation, and teaching. As such, it would be beneficial to conduct a similar analysis on these populations in order to investigate what approaches they have that may differ due to their different levels of experience, their different positions within the course staff, and their lack of experience as students in the course.

It is important to note that our results relate to learning assistants' self-described approaches to teaching computation based on interview data. It is possible that analysis of their enacted practices in the classroom may not align with the approaches they profess. Our results give insight into learning assistants' beliefs about teaching computation, which is an essential part of understanding their role and impact in the classroom, but it is not the entire story. Our results would be well complemented by an investigation into how learning assistants actually teach in the classroom, and how those observed practices align or do not align with the approaches they described when interviewed.

The themes and variations identified here do not fully describe the experiences of learning assistants that were interviewed. As a method, phenomenography seeks to build the most concise categories that capture the variations uncovered in the experiences of the participants. This means that not every element of each learning assistant's experience was captured in the categories, because it is the crucial variations in experiences that are the focus of analysis. While this does result in the loss of some of the nuance in each individual's experience, it is also what lends phenomenography its strength as a method for finding commonalities and variations in the experiences of a collective. It is worth noting that phenomenographic studies typically use sample sizes of 15-20 participants [88], and that 12 learning assistants were interviewed for this study. While we do not believe that interviewing more learning assistants from $\mathrm{P}$ Cubed would drastically change our results, it is possible that such additional data could provide some refinement.

\section{CONCLUSION}

The work presented here provides valuable insight into learning assistants' experiences teaching computation. The identification of the teaching approaches identified here provides a framework that can be used to understand what course goals our learning assistants are taking up, and could also be applied to investigate how their approaches develop over time or to determine if similar teaching approaches emerge in other contexts. As more physics courses incorporate computational problems into their curricula, and as more courses shift towards collaborative learning environments that may require teaching to be delegated to learning assistants, it will be important to understand the approaches that instructors take to teaching in these environments. Better understanding these approaches and how to influence them can allow us to best support instructors as they facilitate students' learning in these complex environments.

\section{ACKNOWLEDGMENTS}

We thank R. Sekhar Chivukula, Melanie Cooper, Vashti Sawtelle, Stuart Tessmer, and the members of the Physics Education Research Laboratory at Michigan State University for their thoughtful feedback and guidance on this work. This work was supported by Michigan State University's College of Natural Science and the CREATE for STEM Institute.

\section{APPENDIX A: SAMPLE COMPUTATIONAL PROBLEM}

The following Appendix provides an example of a computational problem that is taught in the course in which the study presented here took place. In the class session before the students solve the problem here, they solve analytically for the radius and speed of geostationary orbit. This problem requests that they now model their solution computationally. The problem statement, the VPython code students are provided, and an example of correctly modified code are presented here.

\section{Problem statement}

Carver is impressed with your work, but remains unconvinced by your predictions. He has asked you to write a simulation that models the orbit of the satellite. To truly convince Carver, the simulation should include representations of the net force acting on the spacecraft, which has a mass of $15 \times 10^{3} \mathrm{~kg}$. Your simulation should be generalized enough to model other types of orbits including elliptical ones.

\section{Given code}

\footnotetext{
from _ future _ import division

from visual import *

from visual.graph import $*$

from physutil import *
} 
\#Window setup

scene.range $=7 \mathrm{e} 7$

scene. width $=1024$

scene.height $=760$

\#Objects

Earth $=$ sphere $($ pos $=$ vector $(0,0,0)$, radius $=6.4 \mathrm{e} 6$, material $=$ materials.BlueMarble $)$

Satellite $=$ sphere $(\operatorname{pos}=\operatorname{vector}(7 *$ Earth.radius, 0,0$)$, radius $=1 \mathrm{e} 6$, color $=$ color.red, make_trail $=$ True $)$

\#Parameters and Initial Conditions

mSatellite $=1$

pSatellite $=$ vector $(0,5000,0)$

\#Time and time step

$\mathrm{t}=0$

$\mathrm{tf}=60 * 60 * 24$

$\mathrm{dt}=1$

\#MotionMap/Graph

SatelliteMotionMap = MotionMap (Satellite, tf, 20, markerScale=2000, labelMarkerOrder=False)

\#Calculation Loop

while $\mathrm{t}<\mathrm{tf}$ :

rate $(10000)$

Fnet $=$ vector $(0,0,0)$

pSatellite $=$ pSatellite + Fnet ${ }^{*} \mathrm{dt}$

Satellite.pos $=$ Satellite.pos $+(\text { pSatellite } / \mathrm{mSatellite})^{*} \mathrm{dt}$

SatelliteMotionMap.update (t, pSatellite/mSatellite)

$\mathrm{t}=\mathrm{t}+\mathrm{dt}$

\#Earth Rotation (IGNORE)

theta $=7.29 \mathrm{e}-5 * \mathrm{dt}$

Earth.rotate $($ angle $=$ theta, axis=vector $(0,0,1)$, origin=Earth.pos $)$

\section{Example of correctly modified code}

from _ future _ import division

from visual import *

from visual.graph import *

from physutil import *

\#Window setup

scene.range $=7 \mathrm{e} 7$

scene. width $=1024$

scene.height $=760$

\#Objects

Earth $=$ sphere $($ pos $=$ vector $(0,0,0)$, radius $=6.4 \mathrm{e} 6$, material $=$ materials. BlueMarble $)$

Satellite $=$ sphere $(\operatorname{pos}=\operatorname{vector}(4.2 \mathrm{e} 7,0,0)$, radius $=1 \mathrm{e} 6$, color $=$ color.red, make_trail $=$ True $)$

\#Parameters and Initial Conditions

$\mathrm{mSatellite}=15 \mathrm{e} 3$

pSatellite $=$ mSatellite*vector $(0,3073,0)$

$\mathrm{G}=6.67 \mathrm{e}-11$

mEarth $=5.97 \mathrm{e} 24$ 


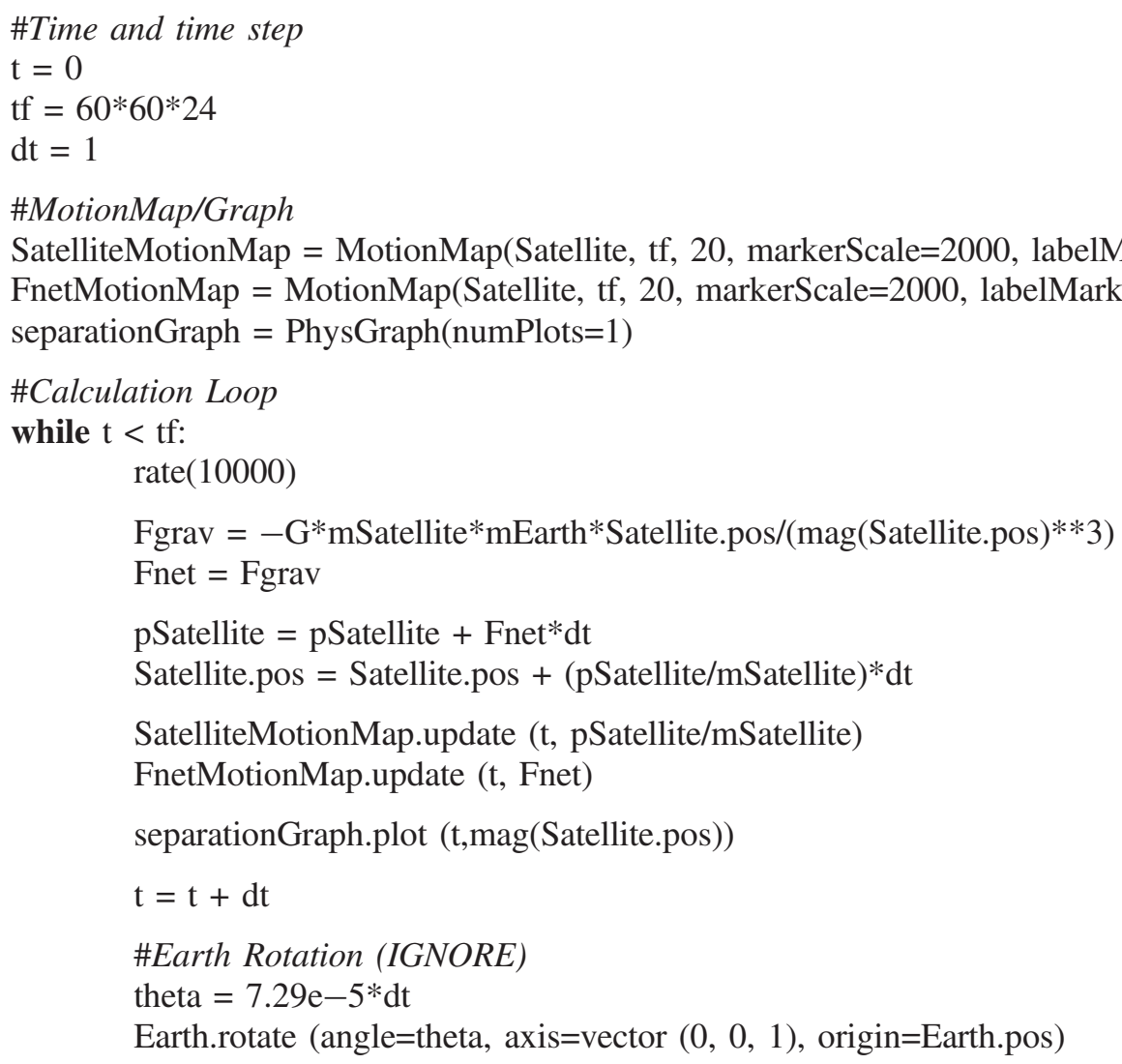

\section{APPENDIX B: INTERVIEW PROTOCOL}

\section{Background}

- What is it like to teach in P-Cubed?

- How long have you been teaching in P-Cubed?

- Did you have any teaching experience prior to P-Cubed? Could you describe it for me?

- Have you had any other teaching experiences since beginning in P-cubed? Can you describe them for me?

- What sort of computational experiences did you have before P Cubed?

- Since teaching in P Cubed have you gained any further computational experiences?

\section{P Cubed context}

- Describe what computation looks like in P-Cubed.

- Describe what a typical computational problem looks like.

- Can you talk about a specific problem?

- What kinds of tasks are students asked to do?

- What is a model? What is modeling?

- Is there a difference between models on analytic days and models on computation days?

- Why do you think the computational problems are designed the way they are?

- What do you think of using VPython?

- How does it impact your teaching?
- What do you think of minimally working programs?

- How do they impact your teaching?

- Why do you think we pick the topics we do for the computational problems?

- Are there any differences among the computational problems?

- What are the learning goals for students are on computation days?

- We give the students some other tools to use, such as the four quadrants and written feedback. Can you describe your experience with those?

- Why do you think we have them?

- How did you use them in your teaching?

- Why do we have students work in groups? Why do computation in groups?

- Why do we have 15 instructors in the room?

- At the beginning of the semester, we have you go through some training about being an LA. Can you tell me your experience of it?

- How did it affect your teaching?

- What do you think the instructors goals for your teaching are?

- During the semester, we have preclass and postclass meetings every week. What was your experience of those?

- Why do you think we have them?

- How did they affect your teaching?

- Do you do anything else to prepare for teaching? 
- We give you solutions including tutor questions. Can you tell me your experience with them?

- What do you think their purpose is?

- How do you use them?

\section{Teaching in $\mathbf{P}$ Cubed}

- Moving into the classroom specifically, can you describe your teaching on a computational week, starting with Tuesday and then moving onto Thursday?

- Are there specific things you do and say? Why?

- Are there specific student actions or comments you watch out for?

- What do you do when you see them happen?

- Are there things you avoid doing? Why?

- How do you decide when to go talk to a group?

- How do you decide when to give information versus give hints versus ask questions?

- Is it affected by the issue being a syntax error versus a conceptual misunderstanding versus something else?

- What kinds of questions do you ask? Why?

- How do you decide whom to ask questions to?

- Where do you want a group to be after you interact with them?

- Do you see groups take different approaches to computational problems?

- How do you deal with those approaches?

- Students often struggle with the geostationary orbit problem. Can you describe what you've experienced and how you handle it?

- What do the students struggle with on computation days?

- Why do you think this is challenging for them?

- How do you help students resolve the issues you've mentioned?

- Do you think students learn from these situations?

- How do you decide when struggling or frustration is okay?
- How does teaching different students affect your teaching? Different groups?

- How do you balance having two groups?

- Do you change how you work with a given group over time?

- What do you see as your role as a teacher in P Cubed?

- What is your role on the teaching team?

\section{General thoughts on teaching}

- How would you describe your general approach to teaching?

- How did you develop that approach?

- How does that apply to computational problems?

- When do you know you have done a good job as a teacher?

- What kind of progress do you look for?

- When do you know that your students have learned something?

- What does understanding mean?

- What shows a student has it?

- Whats the most important thing for students to do in class to learn?

- How does that thing lead to understanding?

- How do you make sure students do that thing?

- Is it important for students to like you? Why?

- By the end of the semester, what is your goal for the students you work with?

- Why did you want to be an LA?

- Why do you think you were chosen to be an LA?

- What do you think you personally bring to the classroom as a teacher?

\section{Closing question}

- Is there anything you'd change about the way P Cubed uses computational problems?
[1] N. R Augustine et al., Rising Above the Gathering Storm: Energizing and Employing America for a Brighter Economic Future (National Academies Press, Washington, DC, 2005), retrieved March 19, 2008.

[2] R. Atkinson and M. Mayo, Refueling the U.S. Innovation Economy: Fresh Approaches to Science, Technology, Engineering and Mathematics (Stem) Education (Information Technology and Innovation Foundation, Washington, DC, 2010).

[3] National Research Council et al., Education for Life and Work: Developing Transferable Knowledge and Skills in the 21st Century (National Academies Press, Washington, DC, 2013).
[4] U. S. National Academy of Engineering, The Engineer of 2020: Visions of Engineering in the New Century (National Academies Press, Washington, DC, 2004).

[5] National Research Council et al., The Mathematical Sciences in 2025 (National Academies Press, Washington, DC, 2013).

[6] National Research Council et al., STEM Integration in K-12 Education: Status, Prospects, and an Agenda for Research (National Academies Press, Washington, DC, 2014).

[7] National Research Council et al., A Framework for K-12 Science Education: Practices, Crosscutting Concepts, and Core Ideas (National Academies Press, Washington, DC, 2012). 
[8] National Research Council et al., Adapting to a Changing World: Challenges and Opportunities in Undergraduate Physics Education (National Academies Press, Washington, DC, 2013).

[9] National Research Council et al, Engineering in $\mathrm{K}-12$ education: Understanding the Status and Improving the Prospects (National Academies Press, Washington, DC, 2009).

[10] S. Singer and K. A. Smith, Discipline-based education research: Understanding and improving learning in undergraduate science and engineering, J. Engin. Educ. 102, 468 (2013).

[11] B. J. S. Barron, D. L. Schwartz, N. J. Vye, A. Moore, A. Petrosino, L. Zech, and J. D. Bransford, Doing with understanding: Lessons from research on problem-and project-based learning, J. Learn. Sci. 7, 271 (1998).

[12] J. S. Krajcik and P. C. Blumenfeld, Project-Based Learning (Cambridge University Press, Cambridge, England, 2006).

[13] K. Cummings, The Rensselaer studio model for learning and teaching: What have we learned, in Proceedings of the National Research Councils Workshop Linking Evidence to Promising Practices in STEM Undergraduate Education (National Research Council, Washington, DC, 2008).

[14] P. B. Kohl and H. Vincent Kuo, Chronicling a successful secondary implementation of studio physics, Am. J. Phys. 80, 832 (2012).

[15] R. Beichner, The Scale-Up Project: A Student-Centered Active Learning Environment for Undergraduate Programs (National Academy of Sciences, Washington, DC, 2008).

[16] E. Brewe, Modeling theory applied: Modeling instruction in introductory physics, Am. J. Phys. 76, 1155 (2008).

[17] E. Etkina and A. Van Heuvelen, Investigative science learning environment - a science process approach to learning physics, Research-based Reform University Phys. 1, 4 (2007).

[18] E. Etkina and A. V. Heuvelen, Investigative Science Learning Environment: Using the processes of science and cognitive strategies to learn physics, in Proceedings of the 2001 Physics Education Research Conference, Rochester, NY (2001).

[19] P. W. Irving, M. J. Obsniuk, and M. D. Caballero, P3: A practice focused learning environment, Eur. J. Phys. 38, 055701 (2017).

[20] D. Raine and S. Symons, Experiences of PBL in physics in UK higher education, PBL in Context Bridging Work and Education, 67 (2005).

[21] K. S. Cockrell, J. A. Hughes Caplow, and J. F. Donaldson, A context for learning: Collaborative groups in the problem-based learning environment, Rev. High. Educ. 23, 347 (2000).

[22] D. H. J. M. Dolmans, S. M. M. Loyens, H. Marcq, and D. Gijbels, Deep and surface learning in problem-based learning: a review of the literature, Adv. Health Sci. Educ. 21, 1087 (2016).

[23] M. Abrandt, R. Castensson, and L.-O. Dahlgren, PBL from the teacher's perspective. conceptions of the tutor's role within problem based learning., Higher Educ. 36, 437 (1998).
[24] G. Maudsley, Roles and responsibilities of the problem based learning tutor in the undergraduate medical curriculum, Br. Med. J. 318, 657 (1999).

[25] S. J. Pollock and N. D. Finkelstein, Sustaining educational reforms in introductory physics, Phys. Rev. ST Phys. Educ. Res. 4, 010110 (2008).

[26] B. T. Spike and N. D. Finkelstein, Preparing tutorial and recitation instructors: A pedagogical approach to focusing attention on content and student reasoning, Am. J. Phys. 80, 1020 (2012).

[27] V. Otero, S. Pollock, and N. Finkelstein, A physics departments role in preparing physics teachers: The colorado learning assistant model, Am. J. Phys. 78, 1218 (2010).

[28] G. E. Gardner and M. G. Jones, Pedagogical preparation of the science graduate teaching assistant: Challenges and implications, Sci. Educat. 20, 31 (2011).

[29] K. E. Gray and V. K. Otero, Analysis of former learning assistants views on cooperative learning, AIP Conf. Proc. 1179, 149 (2009).

[30] K. E. Gray, D. C. Webb, and V. K. Otero, Effects of the learning assistant model on teacher practice, Phys. Rev. Phys. Educ. Res. 12, 020126 (2016).

[31] K. Gray and V. Otero, Analysis of learning assistants views of teaching and learning, AIP Conf. Proc. 1064, 123 (2008).

[32] NGSS Lead States, Next Generation Science Standards: For States, By States (National Academies Press, Washington, DC, 2013).

[33] E. Behringer and L. Engelhardt, Guest editorial: AAPT recommendations for computational physics in the undergraduate physics curriculum, and the partnership for integrating computation into undergraduate physics, Am. J. Phys. 85, 325 (2017).

[34] D. T. Kaplan, Teaching computation to undergraduate scientists, ACM SIGCSE Bull. 36, 358 (2004).

[35] D. H. McIntyre, J. Tate, and C. A. Manogue, Integrating computational activities into the upper-level paradigms in physics curriculum at oregon state university, Am. J. Phys. 76, 340 (2008).

[36] M. D. Caballero, M. A. Kohlmyer, and M. F. Schatz, Implementing and assessing computational modeling in introductory mechanics, Phys. Rev. ST Phys. Educ. Res. 8, 020106 (2012).

[37] M. D. Caballero, J. B. Burk, J. M. Aiken, B. D. Thoms, S. S. Douglas, E. M. Scanlon, and M. F. Schatz, Integrating numerical computation into the modeling instruction curriculum, Phys. Teach. 52, 38 (2014).

[38] R. Chabay and B. Sherwood, Computational physics in the introductory calculus-based course, Am. J. Phys. 76, 307 (2008).

[39] B. Sherin, A. A diSessa, and D. Hammer, Dynaturtle revisited: Learning physics through collaborative design of a computer model, Interact. Learn. Environ. 3, 91 (1993).

[40] S. Booth, On phenomenography, learning and teaching, Higher Educ. Res. Dev. 16, 135 (1997).

[41] K. Trigwell and M. Prosser, Towards an understanding of individual acts of teaching and learning, Higher Educ. Res. Dev. 16, 241 (1997). 
[42] P. Kinnunen and B. Simon, Phenomenography and grounded theory as research methods in computing education research field, Comput. Sci. Educ. 22, 199 (2012).

[43] M. Tight, Phenomenography: The development and application of an innovative research design in higher education research, Int. J. Social Res. Methodology 19, 319 (2016).

[44] D. Boud and G. Feletti, The Challenge of Problem-Based Learning (Psychology Press, London, 1997).

[45] H. S. Barrows, R. M. Tamblyn et al., Problem-Based Learning: An Approach to Medical Education (Springer Publishing Company, New York, 1980).

[46] M. McParland, L. M. Noble, and G. Livingston, The effectiveness of problem-based learning compared to traditional teaching in undergraduate psychiatry, Med. Educ. 38, 859 (2004).

[47] P. van Kampen, C. Banahan, M. Kelly, E. McLoughlin, and E. O'Leary, Teaching a single physics module through problem based learning in a lecture-based curriculum, Am. J. Phys. 72, 829 (2004).

[48] G. S. Selcuk et al., The effects of problem-based learning on pre-service teachers achievement, approaches and attitudes towards learning physics, Int. J. Phys. Sci. 5, 711 (2010).

[49] F. Dochy, M. Segers, P. Van den Bossche, and D. Gijbels, Effects of problem-based learning: A meta-analysis, Learning Instr. 13, 533 (2003).

[50] M. Sahin, Effects of problem-based learning on university students epistemological beliefs about physics and physics learning and conceptual understanding of Newtonian mechanics, J. Sci. Educ. Technol. 19, 266 (2010).

[51] S. Ahlfeldt, S. Mehta, and T. Sellnow, Measurement and analysis of student engagement in university classes where varying levels of PBL methods of instruction are in use, Higher Educ. Res. Dev. 24, 5 (2005).

[52] E. H. Chiriac, A scheme for understanding group processes in problem-based learning, Higher Educ. 55, 505 (2008).

[53] V. Otero, S. Pollock, R. McCray, and N. Finkelstein, Who is responsible for preparing science teachers?, Science 313, 445 (2006).

[54] R. M. Goertzen, E. Brewe, L. H. Kramer, L. Wells, and D. Jones, Moving toward change: Institutionalizing reform through implementation of the learning assistant model and open source tutorials, Phys. Rev. ST Phys. Educ. Res. 7, 020105 (2011).

[55] E. W. Close, J. Conn, and H. G. Close, Becoming physics people: Development of integrated physics identity through the learning assistant experience, Phys. Rev. Phys. Educ. Res. 12, 010109 (2016).

[56] L. C. McDermott and P. S. Shaffer, The physics education group at the University of Washington, Tutorials in Introductory Physics (Pearson, London, UK, 2002).

[57] K. Perkins, W. Adams, M. Dubson, N. Finkelstein, S. Reid, C. Wieman, and R. LeMaster, PHET: Interactive simulations for teaching and learning physics, Phys. Teach. 44, 18 (2006).

[58] A. A. diSessa and H. Abelson, Boxer: A reconstructible computational medium, Commun. ACM 29, 859 (1986).

[59] E. F. Redish and J. M. Wilson, Student programming in the introductory physics course: Muppet (2000).
[60] C. S. Bruce and C. A. McMahon, Contemporary developments in teaching and learning introductory programming: Towards a research proposal, Faculty of Information Technology, QUT Teaching \& Learning Report (Faculty of Information Technology, Teaching and Learning Committee, Brisbane, Australia, 2002).

[61] R. McCauley, S. Fitzgerald, G. Lewandowski, L. Murphy, B. Simon, L. Thomas, and C. Zander, Debugging: a review of the literature from an educational perspective, Comput. Sci. Educ. 18, 67 (2008).

[62] U. Wilensky and K. Reisman, Thinking like a wolf, a sheep, or a firefly: Learning biology through constructing and testing computational theoriesan embodied modeling approach, Cognit. Instr. 24, 171 (2006).

[63] N. Shah, C. M Lewis, R. Caires, N. Khan, A. Qureshi, D. Ehsanipour, and N. Gupta, Building equitable computer science classrooms: elements of a teaching approach, in Proceeding of the 44th ACM Technical Symposium on Computer Science Education (ACM, New York, 2013), pp. 263-268.

[64] C. M. Lewis and N. Shah, How equity and inequity can emerge in pair programming, in Proceedings of the Eleventh Annual International Conference on International Computing Education Research (ACM, New York, 2015), pp. 41-50.

[65] C. Bruce, L. Buckingham, J. Hynd, C. McMahon, M. Roggenkamp, and I. Stoodley, Ways of experiencing the act of learning to program: A phenomenographic study of introductory programming students at university, J. Inf. Technol. Educ.: Res. 3, 145 (2004).

[66] M. L. Niess, Preparing teachers to teach science and mathematics with technology: Developing a technology pedagogical content knowledge, Teaching Teacher Educ. 21, 509 (2005).

[67] M. J. Koehler and P. Mishra, What happens when teachers design educational technology? The development of technological pedagogical content knowledge, J. Educ. Comput. Res. 32, 131 (2005).

[68] R. Yerrick and T. Hoving, Obstacles confronting technology initiatives as seen through the experience of science teachers: A comparative study of science teachers' beliefs, planning, and practice, J. Sci. Educ. Technol. 8, 291 (1999).

[69] S. Hennessy, J. Wishart, D. Whitelock, R. Deaney, R. Brawn, L. La Velle, A. McFarlane, K. Ruthven, and M. Winterbottom, Pedagogical approaches for technologyintegrated science teaching, Comput. Educ. 48, 137 (2007).

[70] A. J. Magana, S. P. Brophy, and G. M. Bodner, Instructors' intended learning outcomes for using computational simulations as learning tools, J. Eng. Educ. 101, 220 (2012).

[71] F. Marton and L. Svensson, Conceptions of research in student learning, Higher Educ. 8, 471 (1979).

[72] R. Säljö, Learning about learning, Higher Educ. 8, 443 (1979).

[73] F. Marton, Phenomenography describing conceptions of the world around us, Instr. Sci. 10, 177 (1981).

[74] S. Booth, Learning computer science and engineering in context, Comput. Sci. Educ. 11, 169 (2001). 
[75] J. A. Bowden, The nature of phenomenographic research, Phenomenography, 1, 154 (2000).

[76] F. Marton, Phenomenographya research approach to investigating different understandings of reality, J. Thought 28, 21 (1986).

[77] F. Marton and S. Booth, Learning and Awareness (Lawrence Earlbaum, Hillstdale, NJ, 1997).

[78] F. Marton, The idea of phenomenography, in Conference Proceedings, Phenomenography: Philosophy and practice QUT, Brisbane (Centre for Applied Environmental and Social Education Research, Brisbane, Australia, 1994), pp. 7-9.

[79] M. Prosser, K. Trigwell, and P. Taylor, A phenomenographic study of academics' conceptions of science learning and teaching, Learn. Instr. 4, 217 (1994).

[80] D. Bell, The reality of stem education, design and technology teachers perceptions: A phenomenographic study, Int. J. Technol. Des. Educ. 26, 61 (2016).

[81] K. Trigwell, M. Prosser, and P. Taylor, Qualitative differences in approaches to teaching first year university science, Higher Educ. 27, 75 (1994).

[82] C. Englund, A. D. Olofsson, and L. Price, Teaching with technology in higher education: Understanding conceptual change and development in practice, Higher Educ. Res. Dev. 36, 73 (2017).

[83] R. Imafuku, T. Saiki, C. Kawakami, and Y. Suzuki, How do students' perceptions of research and approaches to learning change in undergraduate research?, Int. J. Med. Educ. 6, 47 (2015).
[84] S. A. Weatherford, Student use of physics to make sense of incomplete but functional VPython programs in a lab setting, Ph.D. Thesis, North Carolina State University, 2011.

[85] D. P. Oleynik and P. W. Irving, Scientific practices in minimally working programs, in Proceedings of the 2019 Physics Education Research Conference, Provo, UT (AIP, New York, 2019).

[86] P. Ashworth and U. Lucas, Achieving empathy and engagement: A practical approach to the design, conduct and reporting of phenomenographic research, Studies Higher Educ. 25, 295 (2000).

[87] C. S. Bruce, Reflections on the experience of the phenomenographic interview, Phenomenography: Philosophy and Practice 47 (1994).

[88] K. Trigwell, A phenomenographic interview on phenomenography, Phenomenography 1, 62 (2000).

[89] D. Varnava-Marouchou, Teaching and learning in an undergraduate business context: An inquiry into lecturers' conceptions of teaching and their students' conceptions of learning, Ph.D. Thesis, University of Nottingham, 2008.

[90] N. Entwistle, D. Skinner, D. Entwistle, and S. Orr, Conceptions and beliefs about good teaching: An integration of contrasting research areas, Higher Educ. Res. Dev. 19, 5 (2000).

[91] J. Case and D. Marshall, Between deep and surface: procedural approaches to learning in engineering education contexts, Studies Higher Educ. 29, 605 (2004).

[92] K. Trigwell, M. Prosser, and F. Waterhouse, Relations between teachers' approaches to teaching and students' approaches to learning, Higher Educ. 37, 57 (1999). 